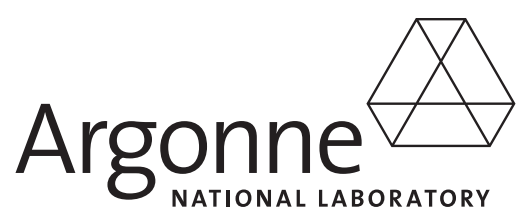

\title{
Annual Report of the International Nuclear Energy Research Initiative OSMOSE Project (FY06)
}

Topical Report

Nuclear Engineering Division 


\begin{abstract}
About Argonne National Laboratory
Argonne is a U.S. Department of Energy laboratory managed by UChicago Argonne, LLC under contract DE-AC02-06CH11357. The Laboratory's main facility is outside Chicago, at 9700 South Cass Avenue, Argonne, Illinois 60439. For information about Argonne, see www.anl.gov.
\end{abstract}

\title{
Availability of This Report
}

This report is available, at no cost, at http://www.osti.gov/bridge. It is also available on paper to the U.S. Department of Energy and its contractors, for a processing fee, from:

U.S. Department of Energy

Office of Scientific and Technical Information

P.O. Box 62

Oak Ridge, TN 37831-0062

phone (865) 576-8401

fax (865) 576-5728

reports@adonis.osti.gov

\begin{abstract}
Disclaimer
This report was prepared as an account of work sponsored by an agency of the United States Government. Neither the United States Government nor any agency thereof, nor UChicago Argonne, LLC, nor any of their employees or officers, makes any warranty, express or implied, or assumes any legal liability or responsibility for the accuracy, completeness, or usefulness of any information, apparatus, product, or process disclosed, or represents that its use would not infringe privately owned rights. Reference herein to any specific commercial product, process, or service by trade name, trademark, manufacturer, or otherwise, does not necessarily constitute or imply its endorsement, recommendation, or favoring by the United States Government or any agency thereof. The views and opinions of document authors expressed herein do not necessarily state or reflect those of the United States Government or any agency thereof, Argonne National Laboratory, or UChicago Argonne, LLC.
\end{abstract}




\section{Annual Report of the International Nuclear Energy Research Initiative OSMOSE Project (FY06)}

Topical Report

by

R. T. Klann and Z. Zhong

Nuclear Engineering Division, Argonne National Laboratory

J. P. Hudelot and N. Drin

Commissariat à l'Energie Atomique, France 


\title{
Annual Report of the
}

\section{International Nuclear Energy Research Initiative OSMOSE Project (FY06)}

\author{
R. T. Klann ${ }^{1}$, JP. Hudelot ${ }^{2}$, N. Drin ${ }^{3}$, Z. Zhong $^{1}$ \\ ${ }^{1}$ Argonne National Laboratory \\ 9700 South Cass Ave. \\ Argonne, IL 60439 \\ US \\ ${ }^{2}$ Commissariat à l'Energie Atomique \\ Cadarache \\ 13109 St Paul lez Durance \\ France \\ ${ }^{3}$ Commissariat à l'Energie Atomique \\ Valrho \\ Pierrelatte - BP 171 \\ 30207 Bagnols-sur-Cèze cedex \\ France
}

September 30, 2006

The submitted manuscript has been created by the University of Chicago Argonne, LLC as Operator of Argonne National Laboratory under Contract No. DE-AC02-06CH11357 with the U.S. Department of Energy. The U.S. Government retains for itself, and others acting on its behalf, a paid-up, nonexclusive, irrevocable worldwide license in said article to reproduce, prepare derivative works, distribute copies to the public, and perform publicly and display publicly, by or on behalf of the Government. 
Project Number: 2004-002-F

Project Title: OSMOSE - An Experimental Program for Improving Neutronic Predictions of Advanced Nuclear Fuels

Lead US Investigating Organization: Argonne National Laboratory US Principal Investigator: Raymond T. Klann

Lead Collaborating Investigating Organization: CEA-Cadarache Lead Collaborating Principal Investigator: Jean-Pascal Hudelot

Other Collaborating Organizations: CEA-Valrho

Reporting Period: October 1, 2005 - September 30, 2006

NTD/SIM: H. Khalil

Work Package \#: G-A0802L01

\section{Project Status Summary:}

The goal of the OSMOSE program is to measure the reactivity effect of minor actinides in known neutron spectra of interest to the Generation-IV reactor program and other programs and to create a database of these results for use as an international benchmark for the minor actinides. The results are then compared to calculation models to verify and validate integral absorption cross-sections for the minor actinides.

The OSMOSE program includes all aspects of the experimental program - including the fabrication of fuel pellets and samples, the oscillation of the samples in the MINERVE reactor for the measurement of the reactivity effect, reactor physics modeling of the MINERVE reactor, and the data analysis and interpretation of the experimental results.

Significant accomplishments in FY06 include: 1. the completion of the oscillation measurements in the R1-UO2 core configuration (PWR-Uox spectrum) for the first 2 sets of OSMOSE samples, 2. the completion of data analysis with both APOLLO2 and DRAGON deterministic calculation codes, respectively in CEA and ANL, and the comparison of experimental results of the first 2 sets of samples in R1-UO2 to calculational results, 3. the fabrication and shipment to CEA Cadarache of the second set of OSMOSE samples, 4. the completion of chemical and isotopic analysis of the first set of samples at CEA Marcoule, 5. the loading of the R1-MOX core configuration in July 2006, 6. the beginning of the oscillation measurements in the R1-MOX core configuration (PWR-MOX spectrum) in September 2006, 7. the publication of the OSMOSE results in R1-UO2 at the PHYSOR2006 conference, including the comparison of experimental results with ANL and CEA calculation results and the publication of four ANL technical reports and three CEA reports related to the OSMOSE project. 


\section{TABLE OF CONTENTS}

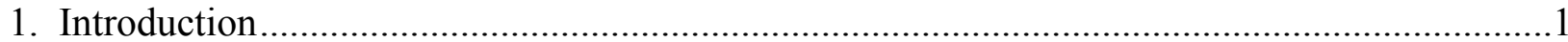

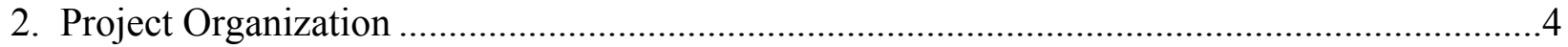

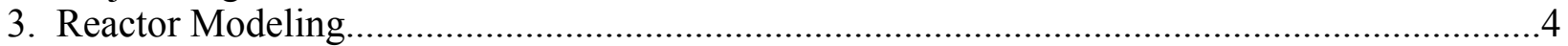

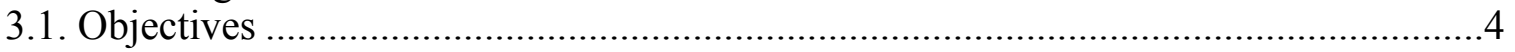

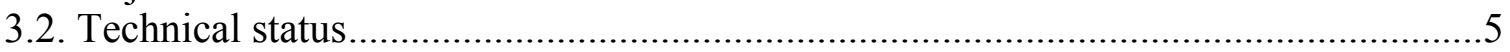

3.2.1. Reactivity-worth calculations - REBUS results ......................................

3.2.2. Reactivity-worth calculations - DRAGON results .......................................

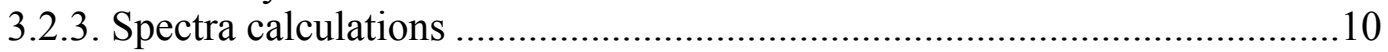

3.2.4. Comparison to spectra from Generation-IV systems ...................................13

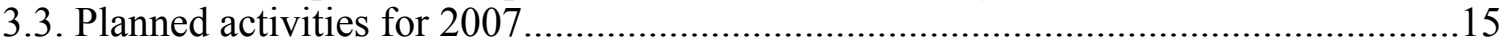

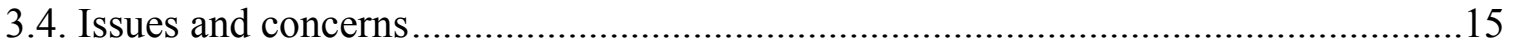

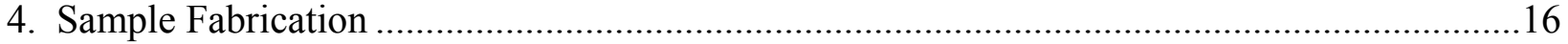

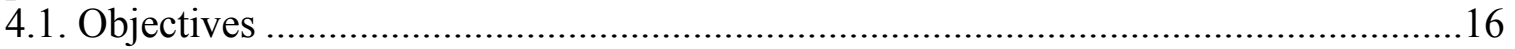

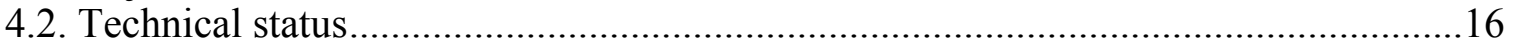

4.2.1. Supply and preparation of isotopes........................................................16

4.2.2. Pellet fabrication .......................................................................................16

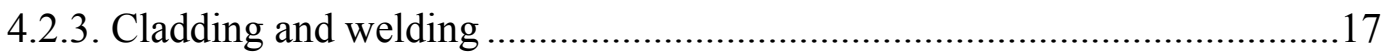

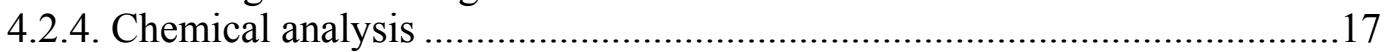

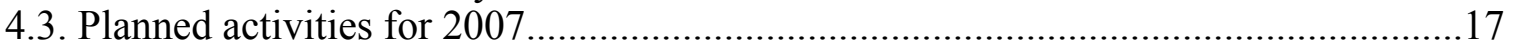

4.4. Issues and concerns .................................................................................. 18

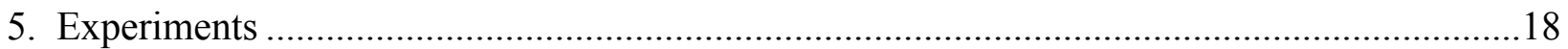

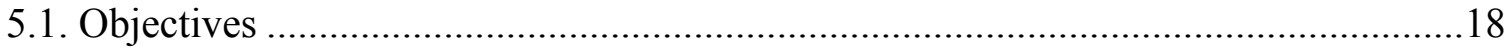

5.2. Technical status.............................................................................................. 19

5.2.1. Oscillation measurements of the first set of OSMOSE samples in the R1-UO2 core configuration ............................................................19

5.2.2. Oscillation measurements of the second set of OSMOSE samples in the R1-UO2 core configuration ………..............................................25

5.2.3. Modified conversion ratio measurements in the R1-UO2 configuration.....28

5.2.4. Oscillation measurements of the first set of OSMOSE samples in

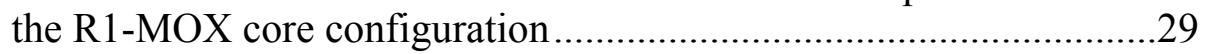

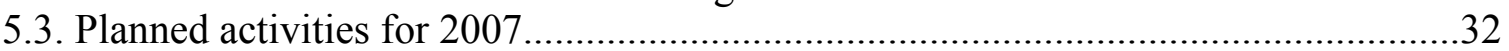

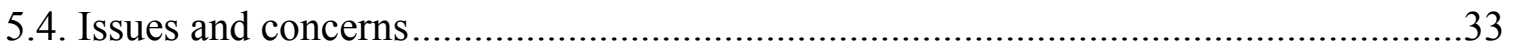

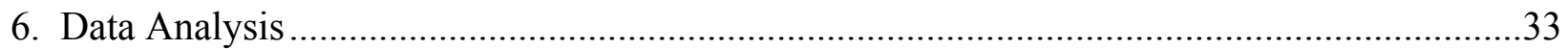

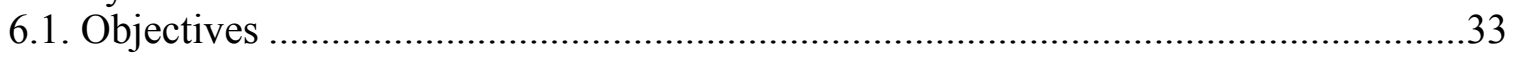

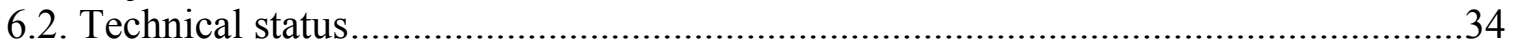

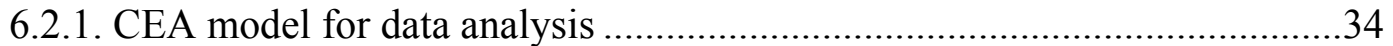

6.2.2. ANL model for data analysis ...................................................................36

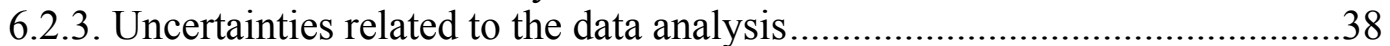

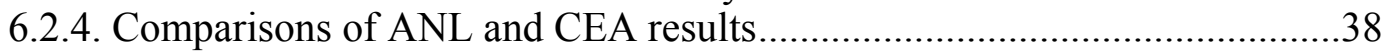

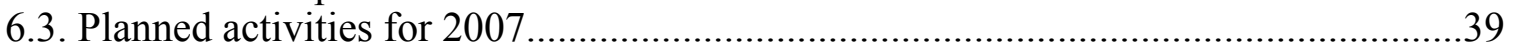

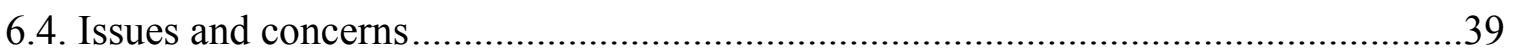

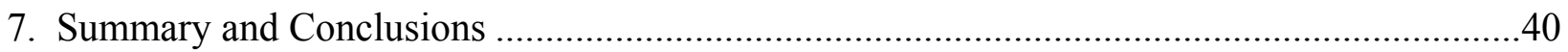

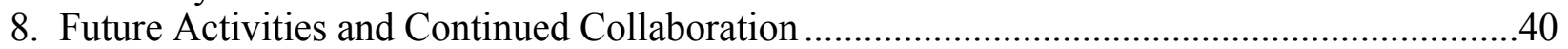

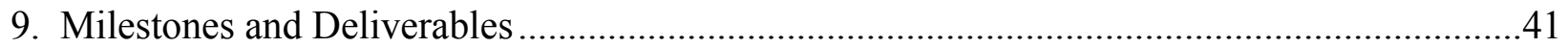

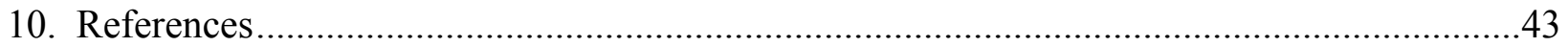




\section{INTRODUCTION}

The design of nuclear systems has shifted over the years from a "test and build" approach to a much more analytical methodology based on the many advances in computational techniques and nuclear data. To a large extent current reactors can be calculated almost as well as they can be measured. This is due in particular to the high quality nuclear data available for the few major isotopes which dominate the neutronics of these systems. Nevertheless, most of the future nuclear systems concepts and advanced fuels development programs currently underway use significant quantities of minor actinides to address modern day issues such as proliferation resistance and low cost. For example, high burnup fuels contain large quantities of americium and curium. Systems designed for plutonium and minor actinide burning are very sensitive to uncertainties in americium and curium data. There are also several other programs where the minor actinide data are essential. These include the Accelerator Transmutation of Waste concepts, Generation-IV concepts, and Burnup Credit programs.

The need for better nuclear data have been stressed by various organizations throughout the world, and results of studies have been published which demonstrate that current data are inadequate for designing the projects under consideration [1] [2]. In particular, a Working Party of the OECD has been concerned with identifying these needs [3] and has produced a detailed High Priority Request List for Nuclear Data. The first step in obtaining better nuclear data consists of measuring accurate integral data and comparing it to integrated energy dependent data: this comparison provides a direct assessment of the effect of deficiencies in the differential data. Several US and international programs have indicated a strong desire to obtain accurate integral reaction rate data for improving the major and minor actinide cross sections. Specifically, these include: ${ }^{232} \mathrm{Th},{ }^{233} \mathrm{U},{ }^{234} \mathrm{U},{ }^{235} \mathrm{U},{ }^{236} \mathrm{U},{ }^{238} \mathrm{U},{ }^{237} \mathrm{~Np},{ }^{238} \mathrm{Pu},{ }^{239} \mathrm{Pu},{ }^{240} \mathrm{Pu},{ }^{241} \mathrm{Pu},{ }^{242} \mathrm{Pu},{ }^{241} \mathrm{Am},{ }^{242} \mathrm{Am}$, ${ }^{243} \mathrm{Am},{ }^{242} \mathrm{Cm},{ }^{243} \mathrm{Cm},{ }^{244} \mathrm{Cm},{ }^{245} \mathrm{Cm},{ }^{246} \mathrm{Cm}$, and ${ }^{247} \mathrm{Cm}$. Data on the major actinides (i.e. ${ }^{235} \mathrm{U}$, ${ }^{236} \mathrm{U},{ }^{238} \mathrm{U},{ }^{239} \mathrm{Pu},{ }^{240} \mathrm{Pu},{ }^{241} \mathrm{Pu},{ }^{242} \mathrm{Pu}$, and ${ }^{241} \mathrm{Am}$ ) are reasonably well-known and available in the Evaluated Nuclear Data Files - (JEF, JENDL, ENDF-B). However, information on the minor actinides (i.e. ${ }^{232} \mathrm{Th},{ }^{233} \mathrm{U},{ }^{237} \mathrm{~Np},{ }^{238} \mathrm{Pu},{ }^{242} \mathrm{Am},{ }^{243} \mathrm{Am},{ }^{242} \mathrm{Cm},{ }^{243} \mathrm{Cm},{ }^{244} \mathrm{Cm},{ }^{245} \mathrm{Cm},{ }^{246} \mathrm{Cm}$, and ${ }^{247} \mathrm{Cm}$ ) is less well-known and considered to be relatively poor in some cases, having to rely on models and extrapolation of few data points. This is mainly due to the difficulty of obtaining relatively pure samples of sufficient quantity (up to about one gram) to perform reliable reaction rate measurements.

A large and exhaustive experimental program is underway in the MINERVE reactor facility at CEA-Cadarache. One of the programs - OSMOSE (Oscillation in Minerve of Isotopes in Eupraxic Spectra) - aims at obtaining in different experimental lattices a single and accurate experimental database for separated heavy nuclides.

The objective of the OSMOSE program is to measure very accurate integral reaction rates in representative spectra for the actinides important to future nuclear system designs and to provide the experimental data for improving the basic nuclear data files. These data will support advanced reactors designed for transmutation of waste or plutonium burning, sub-critical systems such as found in advanced accelerator applications, and waste disposal and treatment programs in the area of criticality safety. The OSMOSE program is very generic, in the sense that it will measure these reaction rates over a broad range of isotopes and spectra and will be used to provide guidance to 
all nuclear data programs in the world. The data will provide information valuable to a large number of projects as noted above.

The OSMOSE program [4] will provide precise experimental data (integral absorption crosssections) for a majority of the heavy nuclides important to reactor and nuclear fuel cycle physics ${ }^{232} \mathrm{Th},{ }^{233} \mathrm{U},{ }^{234} \mathrm{U},{ }^{235} \mathrm{U},{ }^{236} \mathrm{U},{ }^{238} \mathrm{U},{ }^{237} \mathrm{~Np},{ }^{238} \mathrm{Pu},{ }^{239} \mathrm{Pu},{ }^{240} \mathrm{Pu},{ }^{241} \mathrm{Pu},{ }^{242} \mathrm{Pu},{ }^{241} \mathrm{Am},{ }^{243} \mathrm{Am},{ }^{244} \mathrm{Cm}$, and ${ }^{245} \mathrm{Cm}$. Table 1 shows the isotopes of interest in the OSMOSE program and highlights which isotopes are critical for the various programs. Table 2 shows the target improvements in the quality of the nuclear data for the listed actinide isotopes. The study of these nuclides is performed on a large range of neutron spectra corresponding to specific experimental lattices (thermal, epithermal, moderated/fast, and fast spectra).

The OSMOSE experimental program will produce very accurate sample worth measurements for a series of actinides in various spectra, from over-moderated thermal spectra to fast spectra. The objective of the analytical program is to make use of this experimental data to establish deficiencies in the basic nuclear data libraries, identify their origins, and propose paths towards correcting them, in coordination with international nuclear data programs.

\begin{tabular}{|c|c|c|c|c|c|c|c|c|}
\hline \multicolumn{7}{|c|}{ TABLE 1 } \\
\hline & $\begin{array}{c}\text { JEFF3 } \\
\text { validation }\end{array}$ & $\begin{array}{c}\text { Criticality } \\
\text { Burn-up } \\
\text { credit }\end{array}$ & $\begin{array}{c}\text { Pu } \\
\text { recycling }\end{array}$ & $\begin{array}{c}\text { Transmutation } \\
\text { and } \\
\text { incineration }\end{array}$ & $\begin{array}{c}\text { Decay } \\
\text { Heat } \\
\text { power }\end{array}$ & $\begin{array}{c}\text { Subsurface } \\
\text { long-term } \\
\text { Storage }\end{array}$ & $\begin{array}{c}\text { Reactivity loss } \\
\text { per cycle }\end{array}$ & $\begin{array}{c}\text { Thorium } \\
\text { cycle }\end{array}$ \\
\hline${ }^{232} \mathrm{Th}$ & $\otimes$ & & & & & & & $\otimes$ \\
\hline${ }^{233} \mathrm{U}$ & $\otimes$ & & & & & & & $\otimes$ \\
\hline${ }^{234} \mathrm{U}$ & $\otimes$ & $\otimes$ & & & & & $\otimes$ & \\
\hline${ }^{235} \mathrm{U}$ & $\otimes$ & $\otimes$ & & & & $\otimes$ & $\otimes$ & \\
\hline${ }^{236} \mathrm{U}$ & $\otimes$ & $\otimes$ & & & & & $\otimes$ & \\
\hline${ }^{238} \mathrm{U}$ & $\otimes$ & $\otimes$ & & & & & $\otimes$ & \\
\hline${ }^{237} \mathrm{~Np}$ & $\otimes$ & $\otimes$ & & $\otimes$ & & $\otimes$ & $\otimes$ & \\
\hline${ }^{238} \mathrm{Pu}$ & $\otimes$ & $\otimes$ & $\otimes$ & $\otimes$ & $\otimes$ & $\otimes$ & $\otimes$ & \\
\hline${ }^{239} \mathrm{Pu}$ & $\otimes$ & $\otimes$ & $\otimes$ & $\otimes$ & $\otimes$ & $\otimes$ & $\otimes$ & \\
\hline${ }^{240} \mathrm{Pu}$ & $\otimes$ & $\otimes$ & $\otimes$ & $\otimes$ & $\otimes$ & $\otimes$ & $\otimes$ & \\
\hline${ }^{241} \mathrm{Pu}$ & $\otimes$ & $\otimes$ & $\otimes$ & $\otimes$ & $\otimes$ & $\otimes$ & $\otimes$ & \\
\hline${ }^{242} \mathrm{Pu}$ & $\otimes$ & $\otimes$ & $\otimes$ & $\otimes$ & $\otimes$ & $\otimes$ & $\otimes$ & \\
\hline${ }^{241} \mathrm{Am}$ & $\otimes$ & $\otimes$ & $\otimes$ & $\otimes$ & $\otimes$ & $\otimes$ & $\otimes$ & \\
\hline${ }^{243} \mathrm{Am}$ & $\otimes$ & $\otimes$ & $\otimes$ & $\otimes$ & $\otimes$ & $\otimes$ & $\otimes$ & \\
\hline${ }^{244} \mathrm{Cm}$ & $\otimes$ & $\otimes$ & $\otimes$ & $\otimes$ & $\otimes$ & $\otimes$ & $\otimes$ & \\
\hline${ }^{245} \mathrm{Cm}$ & $\otimes$ & $\otimes$ & & $\otimes$ & $\otimes$ & $\otimes$ & $\otimes$ & \\
\hline
\end{tabular}




\begin{tabular}{|c|c|c|c|}
\hline \multicolumn{4}{|c|}{ Table 2 } \\
Target Improvements in Nuclear Data for the OSMOSE Program
\end{tabular}

Ir $=$ resonance integral, $\sigma_{i}^{\text {th }}=$ microscopic capture cross section, $\eta=$ reproduction factor

The measurement program is utilizing the MINERVE reactor at CEA-Cadarache, which is a lowpower uranium fueled pool reactor. The normal accuracy for small-worth samples in this reactor is on the order of $1 \%$ for relative reactivity-worth measurements and $2 \%$ for absolute reactivityworth measurements. The total uncertainty in the OSMOSE samples is estimated to be about 3\% including the uncertainty in the isotopic composition. Reactivity effects of less than $10 \mathrm{pcm}$ (0.0001 or approximately 1.5 cents) will be measured and compared with calibrations to determine the differential reactivity-worth of the sample. Accuracies in small reactivity effects this low are only achieved through oscillation techniques.

Four different neutron spectra will be created in the MINERVE facility: over-moderated $\mathrm{UO}_{2}$ (representative of a fuel processing plant or flooded storage cask), $\mathrm{UO}_{2}$ matrix in water (representative of LWRs), mixed oxide fuel matrix (representative of cores containing MOX fuels), and epithermal spectra (representative of under-moderated reactors). The different spectra are achieved by changing the lattice within the MINERVE reactor.

The OSMOSE program began in 2001 with the preparation of samples. Reactor modifications began in 2002 and were completed in 2003. The measurement program at MINERVE began in 2003 with the qualification of the MINERVE reactor after modifications were complete.

DOE is collaborating with CEA on the OSMOSE program through this project within the Generation-IV Reactor Program and as part of the International Nuclear Energy Research 
Initiative. ANL is serving as the lead laboratory on the U.S. side and CEA-Cadarache is the lead laboratory on the French side. The INERI project is focused on supporting the measurements to be conducted at CEA-Cadarache (through experimental support for conducting the measurements, pre-analysis and planning, and post-measurement data analysis activities). The DOE/CEA collaboration on the OSMOSE program includes the supply of separated ${ }^{240} \mathrm{Pu},{ }^{241} \mathrm{Pu}$, ${ }^{242} \mathrm{Pu}$ and ${ }^{243} \mathrm{Am}$ from DOE, the participation of DOE in the conduct of the experiments, and the development and comparison of analytic tools and models of CEA and DOE based on Monte Carlo and deterministic methods.

The INERI project has been divided into 4 distinct tasks - reactor modeling, sample fabrication, experimental measurements, and data analysis. Within these high level tasks, there are numerous sub-tasks such as reactor modeling of different core configurations and calculations for different core parameters. A lead laboratory has been identified for each high-level task and other supporting laboratory efforts are also noted. The roles and responsibilities for the tasks associated with the OSMOSE project are shown in Table 3.

\section{PROJECT ORGANIZATION}

Roles and Responsibilities for activities and tasks associated with the OSMOSE project are as defined in Table 3.

\begin{tabular}{|l|c|c|}
\hline \multicolumn{3}{|c|}{ Table 3 } \\
\hline \multicolumn{1}{|c|}{ Roles and responsibilities for each organization } \\
\hline Task Description & Lead & Support \\
\hline Task 1: Reactor Modeling & ANL & CEA-Cadarache \\
\hline Task 2: Sample Fabrication & CEA-Valrhô & CEA-Cadarache \\
\hline Task 3: Experiments & CEA-Cadarache & ANL \\
\hline Task 4: Data Analysis & CEA-Cadarache & ANL \\
\hline
\end{tabular}

\section{REACTOR MODELING}

\subsection{Objectives}

The goal of the experimental measurements is to produce a database of reactivity-worth measurements in different neutron spectra for the separated heavy nuclides. This database can then be used as a benchmark for integral reactivity-worth measurements to verify and validate reactor analysis codes.

The analytic effort is being performed by ANL and CEA personnel using MCNP and separate suites of reactor analysis codes. In this manner, a cross comparison can be performed on the results to identify potential errors in the cross-section evaluations in the numerical methods and assumptions used within the codes. This will allow the improvement of these codes. 
The pre-analysis reactor modeling effort provides detailed foreknowledge for planning the experimental measurements. It also allows detailed models of the different core configurations to be assembled which can be used to support the data analysis of the experimental results. This modeling effort also provides the opportunity to thoroughly check the data on the reactor configuration including the fuel and structural materials, composition, geometry, and operating conditions.

\subsection{Technical Status}

\subsubsection{Reactivity-Worth Calculations - REBUS Results}

An initial series of calculations of the reactivity-worth of the OSMOSE samples in the MINERVE reactor with the R1-UO2, R2-UO2 and R1-MOX core configuration were completed. The results are shown in Table 4 and Figure 1.

The results for the reactivity-worth of the samples are compared to the natural uranium sample by subtracting the reactivity of the natural uranium sample value from that of the OSMOSE sample. In this manner, the natural $U$ sample shows a zero value for the reactivity-worth and is considered to be a reference. The samples that show a positive reactivity-worth have a positive reactivity effect compared to natural uranium. That is, replacing the natural uranium sample with the OSMOSE samples causes a net increase in the number of neutrons per generation and hence a positive effect. This effect can be due to an increase of $v$ (the number of neutron per fission) or $\Sigma_{f}$ ( macroscopic fission cross section) or by a decrease in $\Sigma_{a}$ since $k \sim\left(v \Sigma_{f}-\Sigma_{a}\right)$. Samples with a negative reactivity produce a net loss in the number of neutrons per cycle.

\begin{tabular}{|c|c|c|c|c|c|c|}
\hline \multirow{2}{*}{ Samples } & \multicolumn{7}{c|}{ Table 4 } \\
& \multicolumn{2}{|c|}{ Reactivity-worth of OSMOSE samples calculated with REBUS } \\
\cline { 2 - 7 } & k-eff & $\begin{array}{c}\text { reactivity } \\
\text { worth (pcm) }\end{array}$ & k-eff & $\begin{array}{c}\text { reactivity } \\
\text { worth (pcm) }\end{array}$ & k-eff & $\begin{array}{c}\text { reactivity } \\
\text { worth (pcm) }\end{array}$ \\
\hline AM41_1 & 1.000798 & -1.50 & 1.001276 & -2.39 & 0.997427 & -0.50 \\
\hline AM41_2 & 1.000769 & -4.39 & 1.001224 & -7.58 & 0.997418 & -1.41 \\
\hline AM43 & 1.000806 & -0.70 & 1.001290 & -1.00 & 0.997429 & -0.30 \\
\hline NP37_1 & 1.000806 & -0.70 & 1.001288 & -1.17 & 0.997429 & -0.30 \\
\hline NP37_2 & 1.000776 & -3.69 & 1.001233 & -6.68 & 0.997420 & -1.21 \\
\hline PU38 & 1.000776 & -3.69 & 1.001237 & -6.28 & 0.997423 & -0.90 \\
\hline PU39 & 1.000856 & 4.29 & 1.001473 & 17.25 & 0.997443 & 1.11 \\
\hline PU40 & 1.000782 & -3.10 & 1.001258 & -4.19 & 0.997396 & -1.11 \\
\hline PU41 & 1.000820 & 0.70 & 1.001357 & 5.68 & 0.997433 & 0.10 \\
\hline PU42 & 1.000800 & -1.30 & 1.001283 & -1.70 & 0.997426 & -0.60 \\
\hline U233 & 1.000851 & 3.79 & 1.001421 & 12.07 & 0.997444 & 1.21 \\
\hline U234 & 1.000806 & -0.70 & 1.001284 & -1.60 & 0.997430 & -0.20 \\
\hline Unat & 1.000813 & 0 & 1.001300 & 0 & 0.997432 & 0 \\
\hline URE & 1.000878 & 6.49 & 1.001548 & 24.73 & 0.997450 & 1.81 \\
\hline U-TH232 & 1.000809 & -0.40 & 1.001289 & -1.10 & 0.997431 & -0.10 \\
\hline TH232 & 1.000738 & -7.49 & 1.001113 & -18.65 & 0.997409 & -2.31 \\
\hline
\end{tabular}




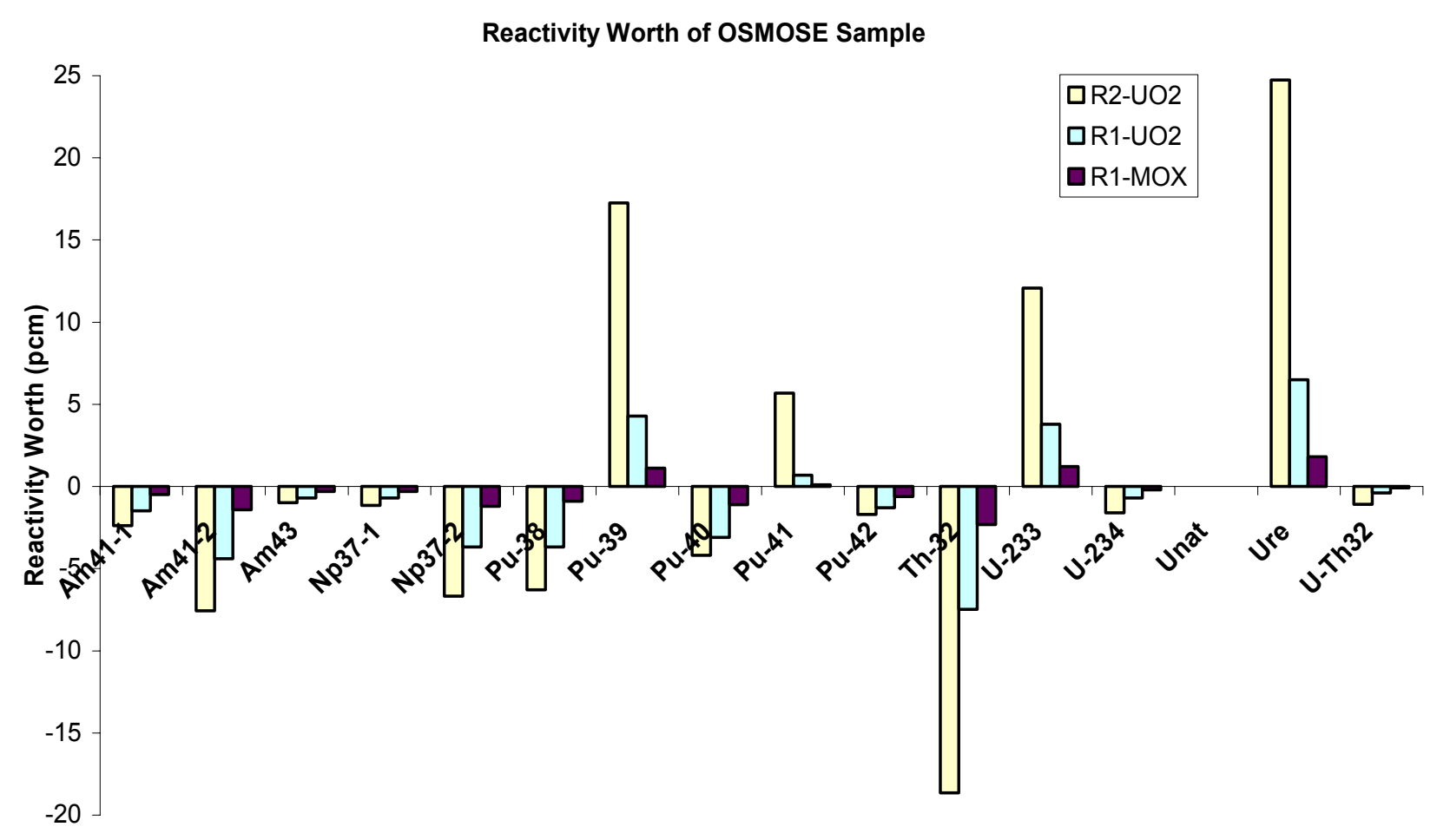

OSMOSE Sample

Figure 1: Reactivity-worth of OSMOSE samples calculated with REBUS

Figure 1 indicates a range of reactivity effect from $-8 \mathrm{pcm}$ to $+8 \mathrm{pcm}$ compared to the natural $\mathrm{U}$ sample for the R1-UO2 configuration, $-25 \mathrm{pcm}$ to $+25 \mathrm{pcm}$ for the R2-UO2 configuration, and $3 \mathrm{pcm}$ to $+3 \mathrm{pcm}$ for the R1-MOX configuration. The trend for the reactivity effect is the same for each sample in all three configurations, however the net effect is different. This is due to the spectral effect of the configurations in that they are highly thermalized spectra. For the R2-UO2 configuration, with a large water region surrounding the sample, the spectrum is much softer so that both the k-eff and the reactivity-worth are the largest among the three core configurations. For the R1-MOX configuration, with the strong absorption of MOX pins, the spectrum is much harder, which makes the k-eff and the reactivity-worth smaller.

It can also be observed from Figure 1 that some samples have positive reactivity worth compared with that of the natural $U$ sample, and other samples have a negative value of reactivity worth. In this case, all three spectra have large thermal neutron fractions. The neutron spectra are shown in Section 3.2.3. The samples that have positive reactivity worth have a larger $\left(v \Sigma_{f}-\Sigma_{a}\right)$ than the natural $U$ sample, most likely due to a higher thermal fission cross section, and the samples that have negative reactivity worth have a smaller $\left(v \Sigma_{f}-\Sigma_{a}\right)$, most likely due to a larger thermal and resonant capture cross section. 


\subsubsection{Reactivity-worth calculations - DRAGON results}

From the results shown in Table 4 and Figure 1, it can be seen that the reactivity-worths for the OSMOSE samples are very small. For some samples, the value is even less than $1 \mathrm{pcm}$, which is difficult to be distinguished from the numerical error, i.e. the truncation and convergence error. This introduces non-trivial uncertainty to the results, especially if we want to compare the reactivity with the experimental signal, which should be proportional to the minor reactivity difference of the core loaded with different samples. To correct for this, a two-dimensional miniature lattice model was introduced using the lattice physics code DRAGON in which the sample should have much larger effect on the reactivity of the system, and the effect of numerical error is significantly reduced.

DRAGON calculations were performed to obtain the reactivity-worth of the OSMOSE samples in the R1-UO2, R2-UO2 and R1-MOX configurations. The results are shown in Table 5 and Figure 2. As before, the reactivity-worth of a sample is referenced to the natural uranium sample.

In the DRAGON calculations, the critical buckling search is superimposed upon the iteration so that the effective multiplication factor $\left(\mathrm{k}_{\text {eff }}\right)$ is forced to 1.0, and using the calculated flux, the infinite multiplication factor $\left(\mathrm{k}_{\text {inf }}\right)$ can be obtained. This value is used as the calculation result for analysis.

\begin{tabular}{|c|c|c|c|c|c|c|}
\hline \multicolumn{7}{|c|}{ Reactivity-worth of OSMOSE samples calculated with DRAGON } \\
\cline { 2 - 8 } Samples & \multicolumn{2}{|c|}{ R1UO2 } & \multicolumn{2}{c|}{ R2UO2 } & \multicolumn{2}{c|}{ R1MOX } \\
\cline { 2 - 8 } & k-eff & $\begin{array}{c}\text { reactivity } \\
\text { worth } \\
\text { (pcm) }\end{array}$ & k-eff & $\begin{array}{c}\text { reactivity } \\
\text { worth } \\
(\mathrm{pcm})\end{array}$ & k-eff & $\begin{array}{c}\text { reactivity } \\
\text { worth } \\
\text { (pcm) }\end{array}$ \\
\hline AM41_1 & 1.316891 & -38.50 & 1.329203 & -59.61 & 1.146963 & -26.14 \\
\hline AM41_2 & 1.315435 & -122.55 & 1.326929 & -188.54 & 1.146197 & -84.41 \\
\hline AM43 & 1.317082 & -27.49 & 1.329687 & -32.22 & 1.146989 & -24.17 \\
\hline NP37_1 & 1.317201 & -20.63 & 1.329705 & -31.21 & 1.147089 & -16.56 \\
\hline NP37_2 & 1.315478 & -120.07 & 1.327088 & -179.51 & 1.146065 & -94.46 \\
\hline PU38 & 1.316010 & -89.34 & 1.327332 & -165.66 & 1.146723 & -44.39 \\
\hline PU39 & 1.318823 & 72.74 & 1.334336 & 229.80 & 1.148068 & 57.77 \\
\hline PU40 & 1.316013 & -89.16 & 1.328228 & -114.84 & 1.146601 & -53.67 \\
\hline PU41 & 1.318219 & 38.00 & 1.331816 & 88.00 & 1.147663 & 27.04 \\
\hline PU42 & 1.317106 & -26.10 & 1.329607 & -36.75 & 1.146955 & -26.75 \\
\hline U233 & 1.319016 & 83.84 & 1.333591 & 187.93 & 1.148303 & 75.60 \\
\hline U234 & 1.317085 & -27.31 & 1.329403 & -48.29 & 1.146993 & -23.86 \\
\hline Unat & 1.317559 & 0.00 & 1.330257 & 0.00 & 1.147307 & 0.00 \\
\hline URE & 1.319550 & 114.52 & 1.336010 & 323.70 & 1.148401 & 83.03 \\
\hline U-TH232 & 1.317279 & -16.13 & 1.325062 & -24.53 & 1.147115 & -14.59 \\
\hline TH232 & 1.315153 & -138.85 & 1.325062 & -294.72 & 1.146250 & -80.37 \\
\hline
\end{tabular}




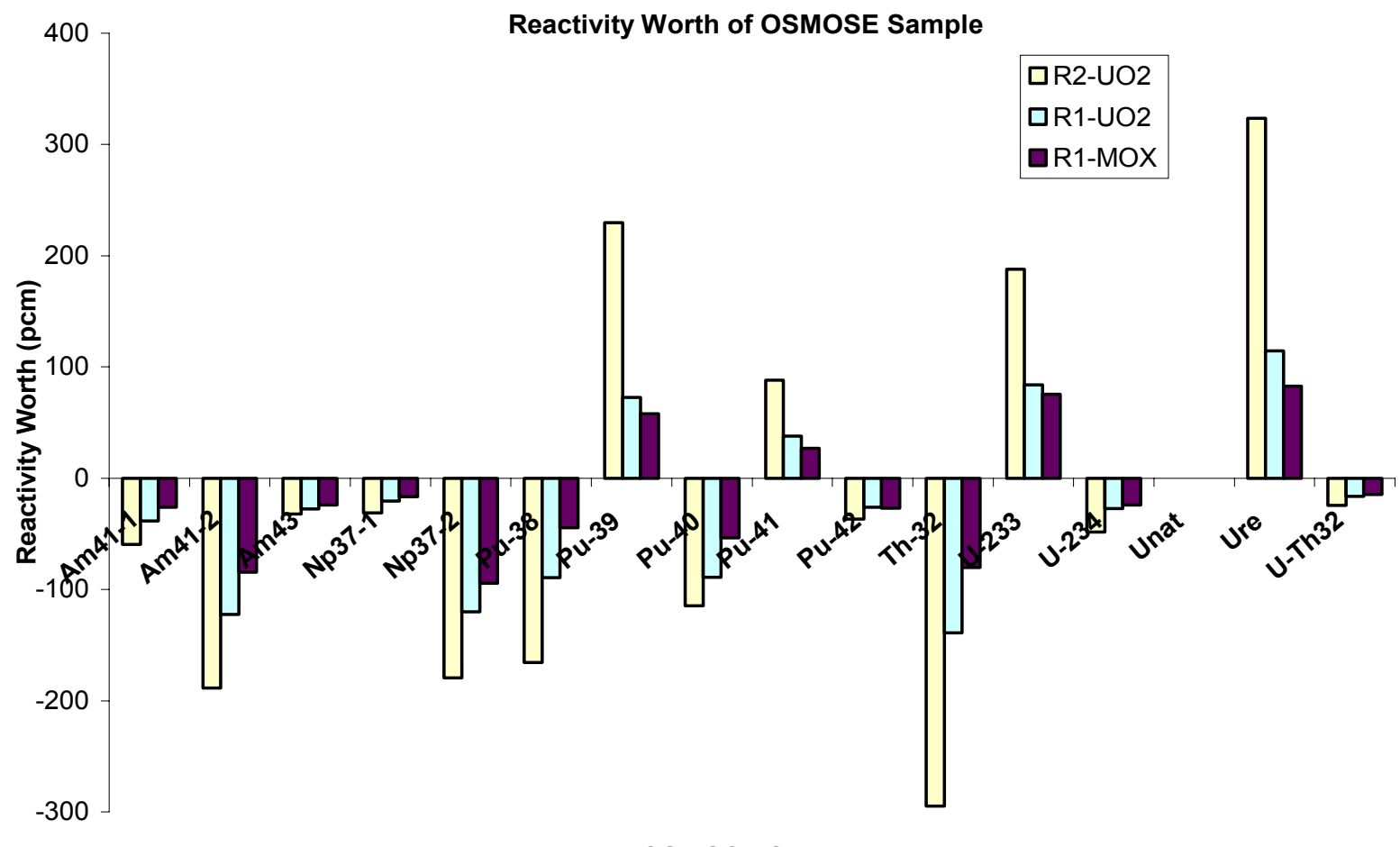

OSMOSE Sample

Figure 2: Reactivity-worth of OSMOSE Samples calculated with DRAGON

To validate the ANL ENDF/B-VI library, a comparison was performed between experimental and calculated results for the R1-UO2 configuration loaded with calibration and oscillation samples. The calculation model is based on lattice physics code DRAGON using ANL 172group ENDF/B-VI library. The process can be summarized as following:

1) Perform calibration measurements, to obtain the experimental signal for

i) calibration samples with well-known cross section

ii) oscillation samples with less well known cross section.

2) Calculate the $k_{\text {inf }}$ for the calibration samples with well known cross section using the validated model, compare it to the experimental signal obtained from step 1) to generate the calibration curve ( linear function).

3) Calculate the $k_{\text {inf }}$ for the oscillation samples with less well known cross sections using the validated model, compare it to the calibration curve obtained from step 2), if there exist apparent difference, it is generally due to the cross section.

For the R1-UO2 configuration, the comparison of calculated results and experimental data has also been performed. Table 6 shows the calculated $k_{\text {inf }}$ of the B-10 and U-235 calibration samples, as well as the experimental signal (in pilot units).

Figure 3 is the calibration curve, which shows the relation between the experimental signal (in pilot units) of the B-10 and U-235 calibration samples, and their calculated eigenvalue (given by the DRAGON 2D model). It has been observed that for the calibration samples, (the composition 
Table 6:

Calculated eigenvalue and experimental signal of the calibration samples

\begin{tabular}{|c|c|c|c|c|}
\hline Sample & $\begin{array}{c}\text { Enrichment of } \\
\text { U235 (wt. \%) }\end{array}$ & $\begin{array}{c}\text { Boron Density } \\
\text { (ppm) }\end{array}$ & $\begin{array}{c}\text { k-eff } \\
\text { Signal }\end{array}$ \\
\hline F0025 & 0.25 & 0 & 1.317135 & 11,126 \\
\hline F0050 & 0.50 & 0 & 1.317345 & 41,846 \\
\hline N0071 & 0.71 & 0 & 1.317518 & 72,001 \\
\hline S0100 & 1.00 & 0 & 1.317765 & 108,544 \\
\hline $\mathbf{S 0 2 0 0}$ & 2.01 & 0 & 1.318487 & 218,290 \\
\hline $\mathbf{S 0 3 0 0}$ & 3.01 & 0 & 1.319121 & 315,012 \\
\hline $\mathbf{S 0 4 0 0}$ & 4.00 & 0 & 1.319715 & 391,359 \\
\hline $\mathbf{S 0 4 9 5}$ & 4.93 & 0 & 1.320190 & 463,613 \\
\hline $\mathbf{1 B 0 1 5 0}$ & 0.25 & 150 & 1.316166 & $-135,504$ \\
\hline $\mathbf{2 B 0 3 3 3}$ & 0.53 & 333 & 1.314937 & $-317,174$ \\
\hline
\end{tabular}

kinf vs. experimental signal

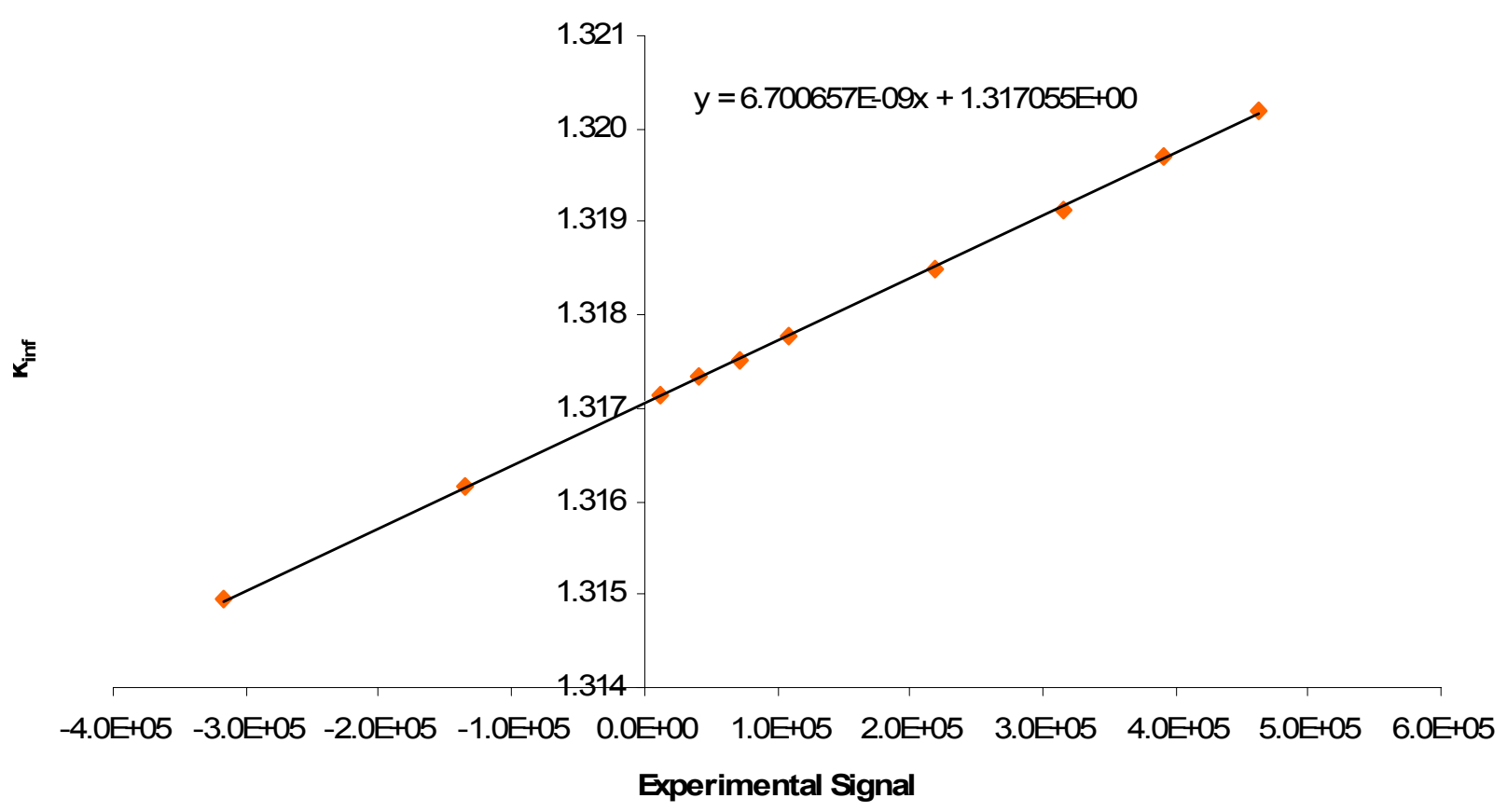

Figure 3: Calibration curve obtained with the DRAGON 2D model 
is UO2 fuel with different enrichments in ${ }^{235} \mathrm{U}$ and with a range of boron concentrations), the calculated reactivity worth is almost perfectly linear with the value of experimental signal, as shown in Figure 3, with RMS less than 0.02. This demonstrates a confidence in the data of major actinides, ${ }^{235} \mathrm{U}$ and ${ }^{238} \mathrm{U}$, in the ANL ENDF/B-VI library.

Additional data analysis using the reactivity-worth calculations and models are described in section 6 .

\subsubsection{Spectra Calculations}

Within the MINERVE reactor, different spectra are achieved by changing the experimental lattice. The R1-UO2 configurations corresponds to an LWR loaded with UO2, the R1-MOX corresponds to LWR loaded with a mixed oxide matrix, the R2-UO2 corresponds to an overmoderated LWR spectrum, and MORGANE/S corresponds to an epithermal spectrum representative of under-moderated reactors. The spectra in the central sample channel of the R1UO2 and R2-UO2 configuration have been calculated by both CEA and ANL with MCNP, using a 99 energy group structures, and the comparison of results is shown in Figure 4 and Figure 5.

The ANL MCNP calculation model is a two-dimensional mini-lattice (11x11 pins) to reduce the computation time, the rest of the experimental zone and the whole driver region are ignored because their contribution to the spectra in the sample region is small.

From Figure 4 and Figure 5, it can be seen that the global spectral shape agrees reasonably well between ANL and CEA results for both R1UO2 and R1MOX configurations, with the thermal peak located at approximately $0.08 \mathrm{eV}$. It is also observed that the ANL spectra is overthermalized compared with that of the CEA result, for both R1UO2 and R1MOX, and there also exists some differences for the local flux peak, which may be due to library differences, (in ANL MCNP calculation, ENDF-VI based library is used.)

The deterministic code DRAGON was also used to calculate the spectra, using the same twodimensional mini-lattice (11x11 pins) model and 172-group neutron library. The DRAGON solution can be used to validate the MCNP results, because MCNP results have relative large standard deviation for detailed solution. Using the same MCNP model, a 172 energy group tally structure was implemented to match the same energy structure as DRAGON library. The comparison of the 172-group spectra calculated with MCNP and DRAGON is shown in Figure 6 for the R1-UO2 configuration and in Figure 7 for the R1-MOX configuration.

It can be seen that the spectra calculated by DRAGON and MCNP agree well for both R1-UO2 R1-MOX configurations, which shows that MCNP can produce correct spectra with detailed energy structure, although in some tally bins the standard deviation is relatively large ( especially for the fast region).

The 172-group spectrum in the R2-UO2 configuration calculated by DRAGON is shown in Figure 8. Compared with Figures 6 and 7, it is observed that the R2-UO2 spectrum is much more thermalized, because eight fuel pins surrounding the sample channel are replaced by water, thus softening the spectrum near the sample region. 


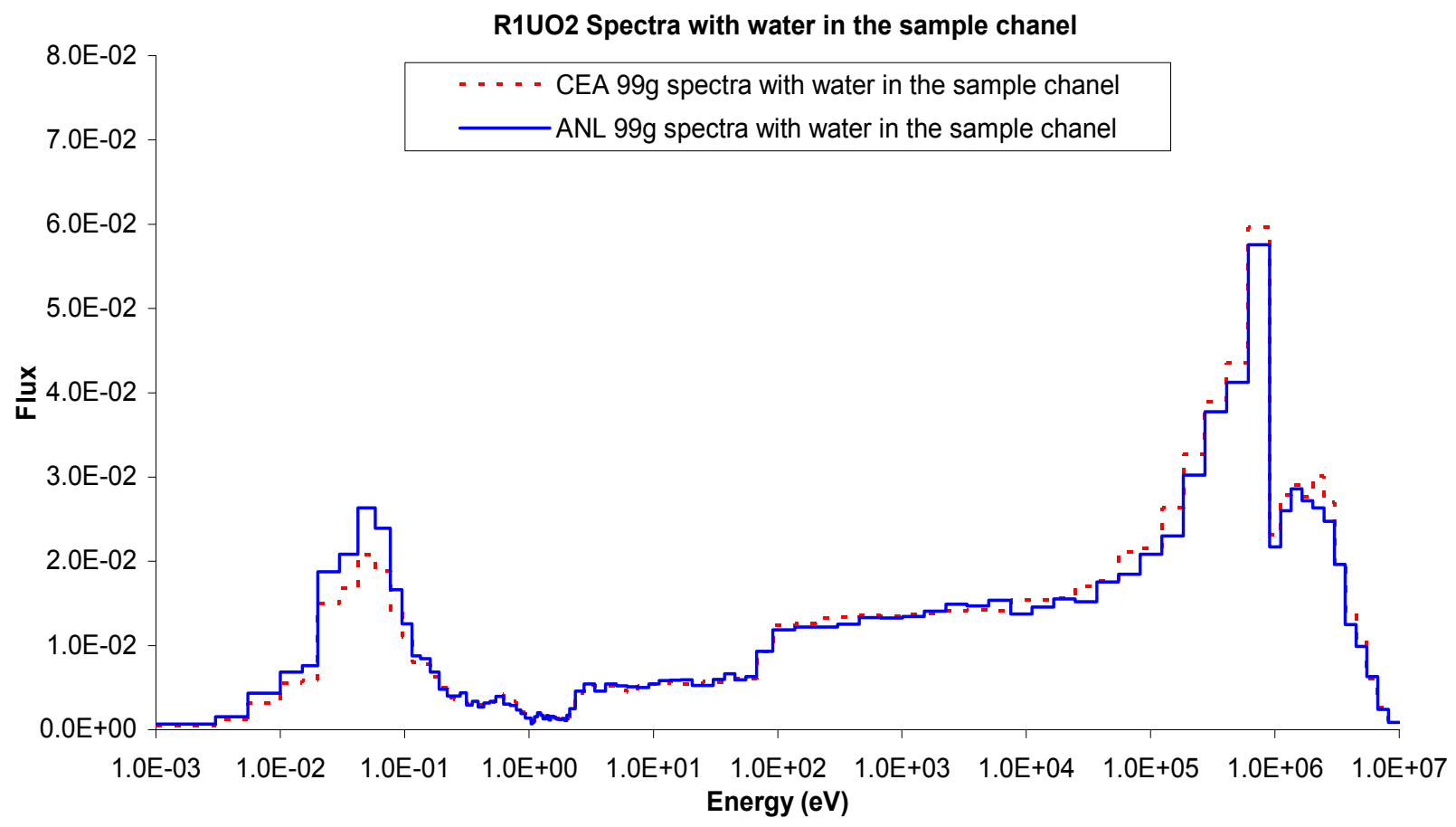

Figure 4: Comparison of 99-group spectra calculated by CEA and ANL for R1-UO2

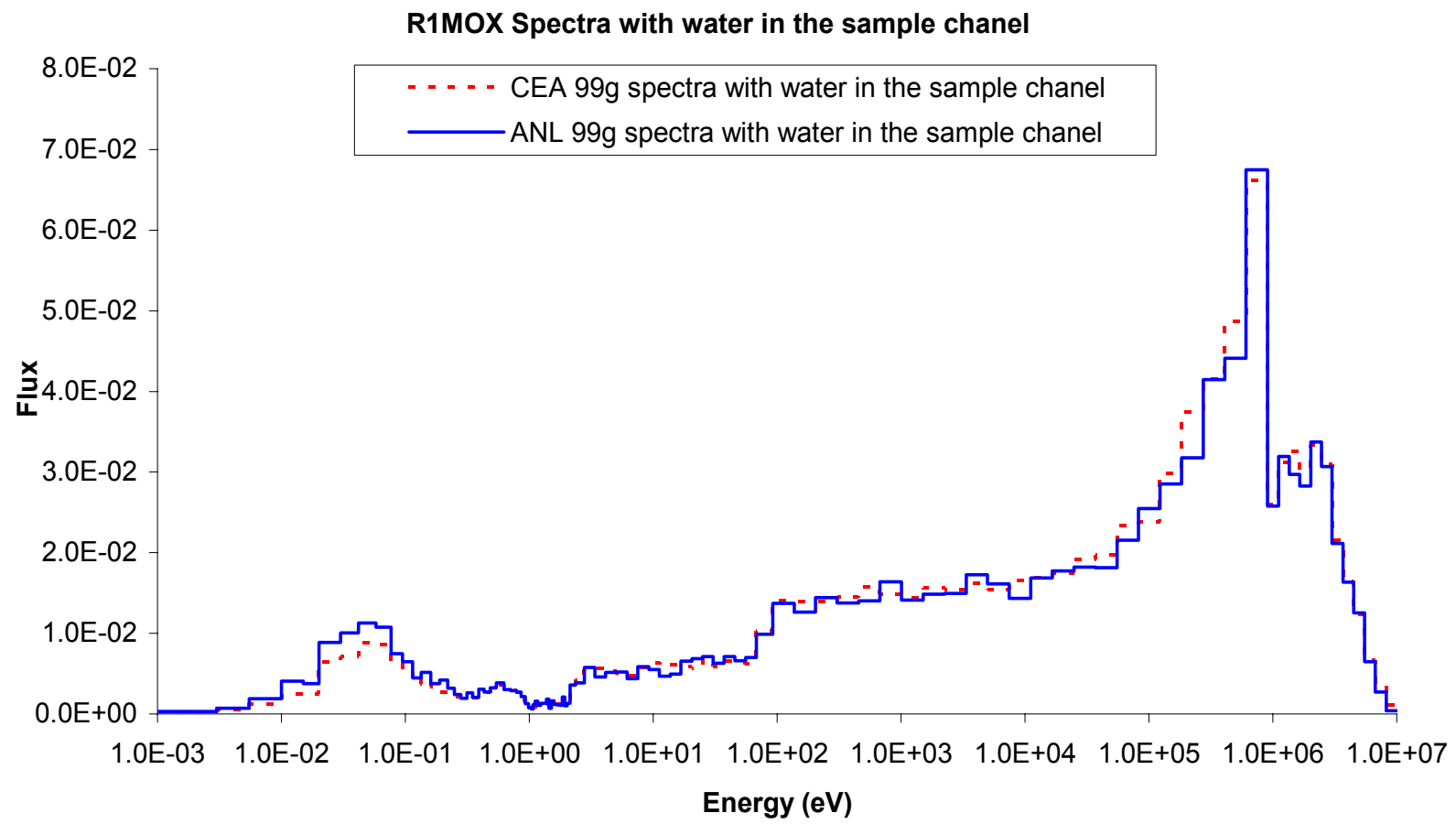

Figure 5: Comparison of 99-group spectra calculated by CEA and ANL for R1-MOX 


\section{2-g Spectra of R1-UO2}

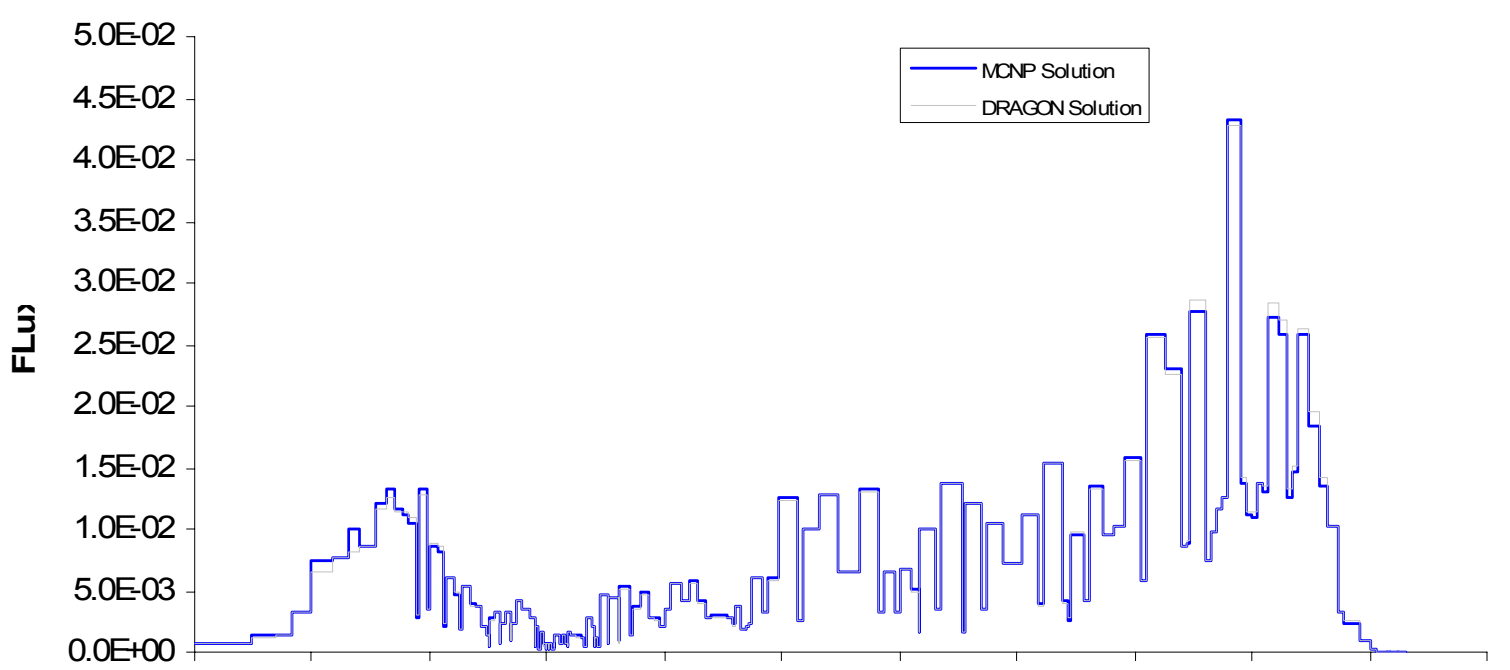

1.0E-03 1.0E-02 1.0E-01 1.0E+00 1.0E+01 1.0E+02 1.0E+03 1.0E+04 1.0E+05 1.0E+06 1.0E+07 1.0E+08 Energy (eV)

Figure 6: 172-group spectra calculated with DRAGON and MCNP for the R1-UO2 configuration

\section{2-g Spectra for R1-MOX}

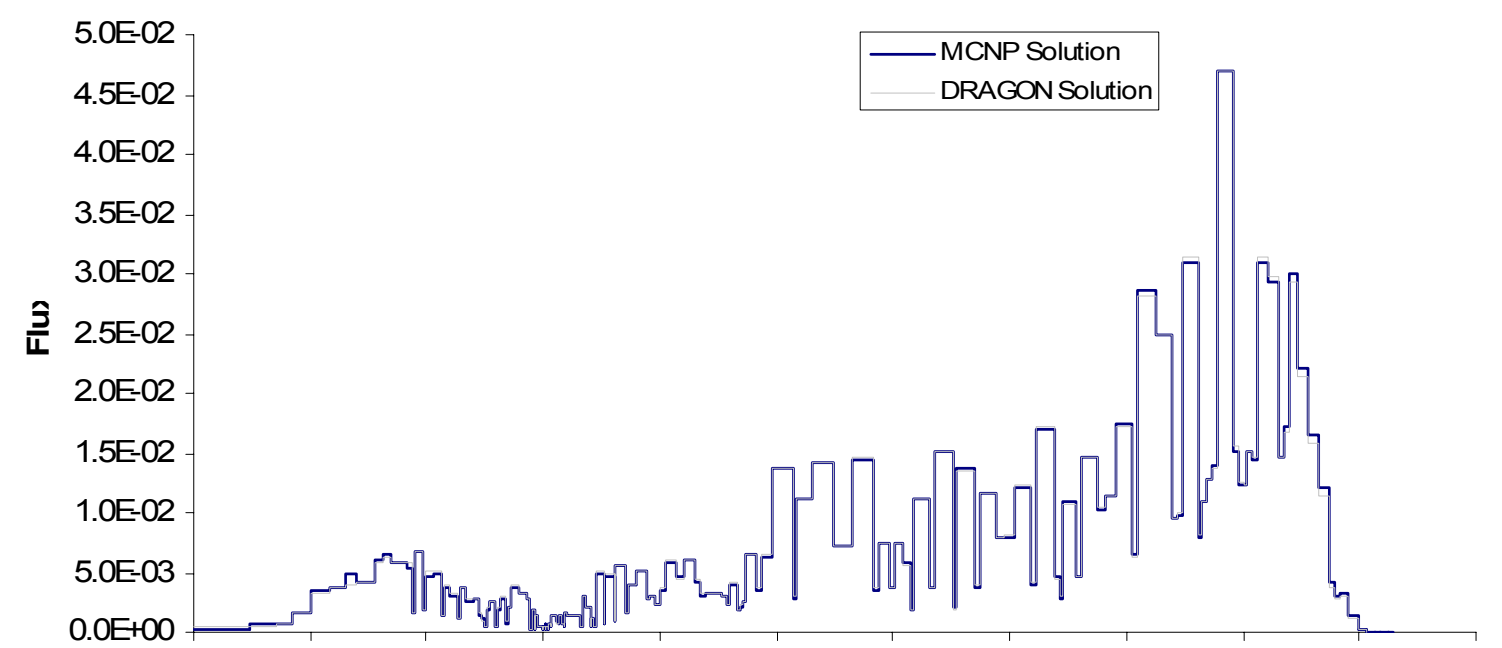

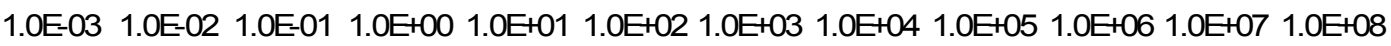
Energy (eV)

Figure 7: 172-group spectra calculated with DRAGON and MCNP for the R1-MOX configuration 


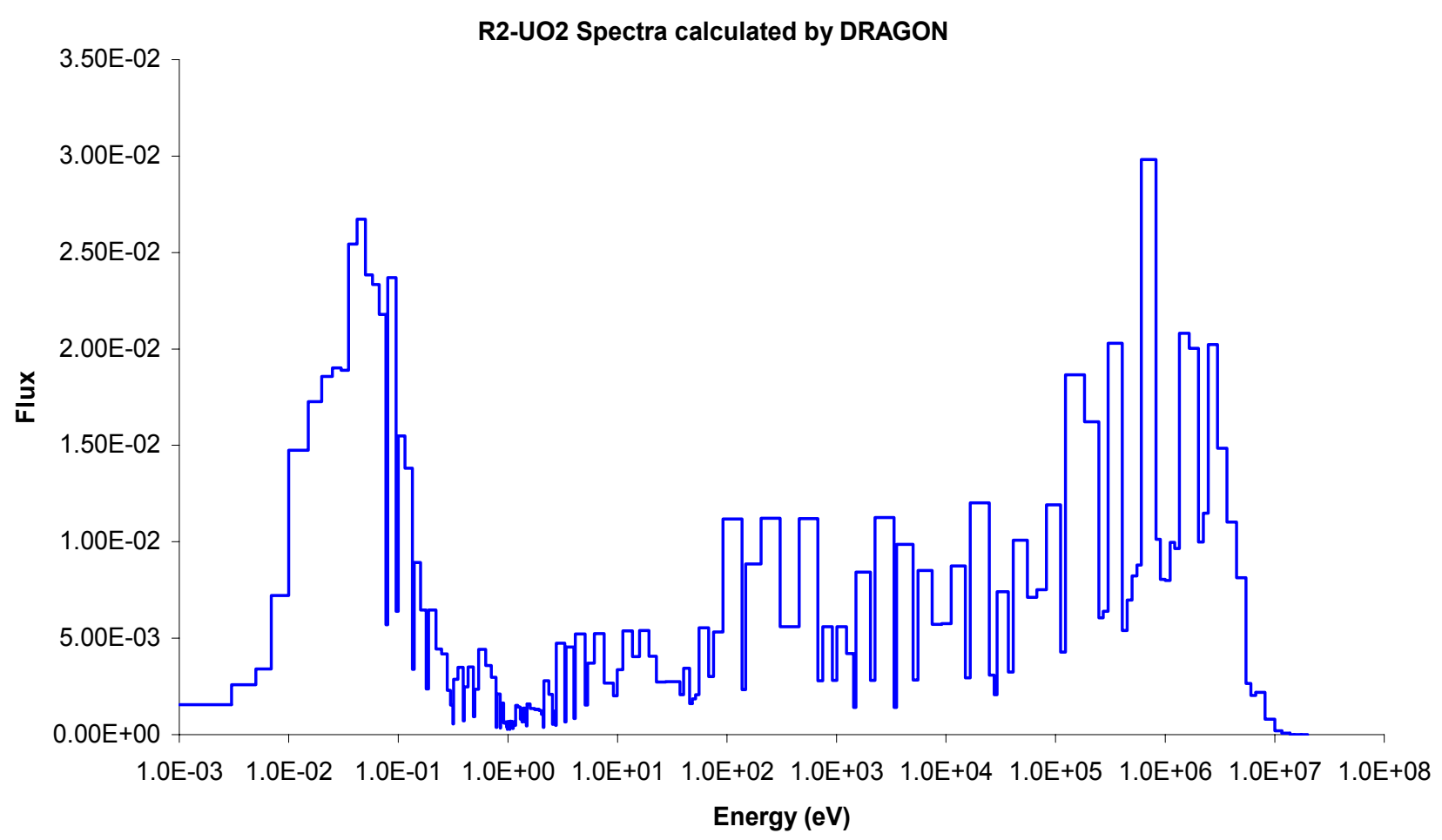

Figure 8: 172-group spectra calculated with DRAGON for the R2-UO2 configuration

\subsubsection{Comparison to spectra from Gen-IV systems}

It is interesting to compare OSMOSE spectra to that obtained from Gen-IV systems, to determine whether the results from the OSMOSE program can be used to validate cross sections of interest to the Gen-IV initiative. The prismatic Very High Temperature Reactor (VHTR) is one of the leading candidates for the Next Generation Nuclear Plant (NGNP) in the U.S. [5] In this design, fuel rods (compacts) are contained in fuel holes in the hexagonal-prismatic fuel elements. Fuel elements also have holes for coolant and control rod material movement, and fuel element handling. The cylindrical fuel compacts contain coated fuel particles (CFPs) dispersed in a graphite matrix. The CFPs give an additional level of heterogeneity within the fuel element.

The 172-group spectrum of a VHTR loaded with oxy-carbide $\left(\mathrm{UC}_{0.5} \mathrm{O}_{1.5}\right)$ coated TRISO fuel particles (U235 enrichment 10.4\%, packing fraction of 0.289, and fuel kernel radius of $385 \mu \mathrm{m}$ ) is shown in Figure 9. Compared with the spectra shown previously for R1-UO2, R2-UO2 and R1-MOX, it can be seen that the shape of the spectrum is very different. For the VHTR spectrum, the epithermal flux is much higher.

The spectrum of the MINERVE reactor loaded with the MORGANE/S configuration has been calculated to compare with the spectrum of the VHTR reactor. For the MORGANE/S configuration, the hexagonal lattice is composed of $11.0 \%$ plutonium mixed oxide fuel pins with a moderating ratio 0.5 , and the radius of fuel pellet is $0.475 \mathrm{~cm}$. A Deep Burn Modular Helium Cooled Reactor (DBMHR) design of VHTR is selected, which is loaded with plutonium oxide fuel particles (packing fraction of 0.20 , and fuel kernel radius of $360 \mu \mathrm{m}$ ). 


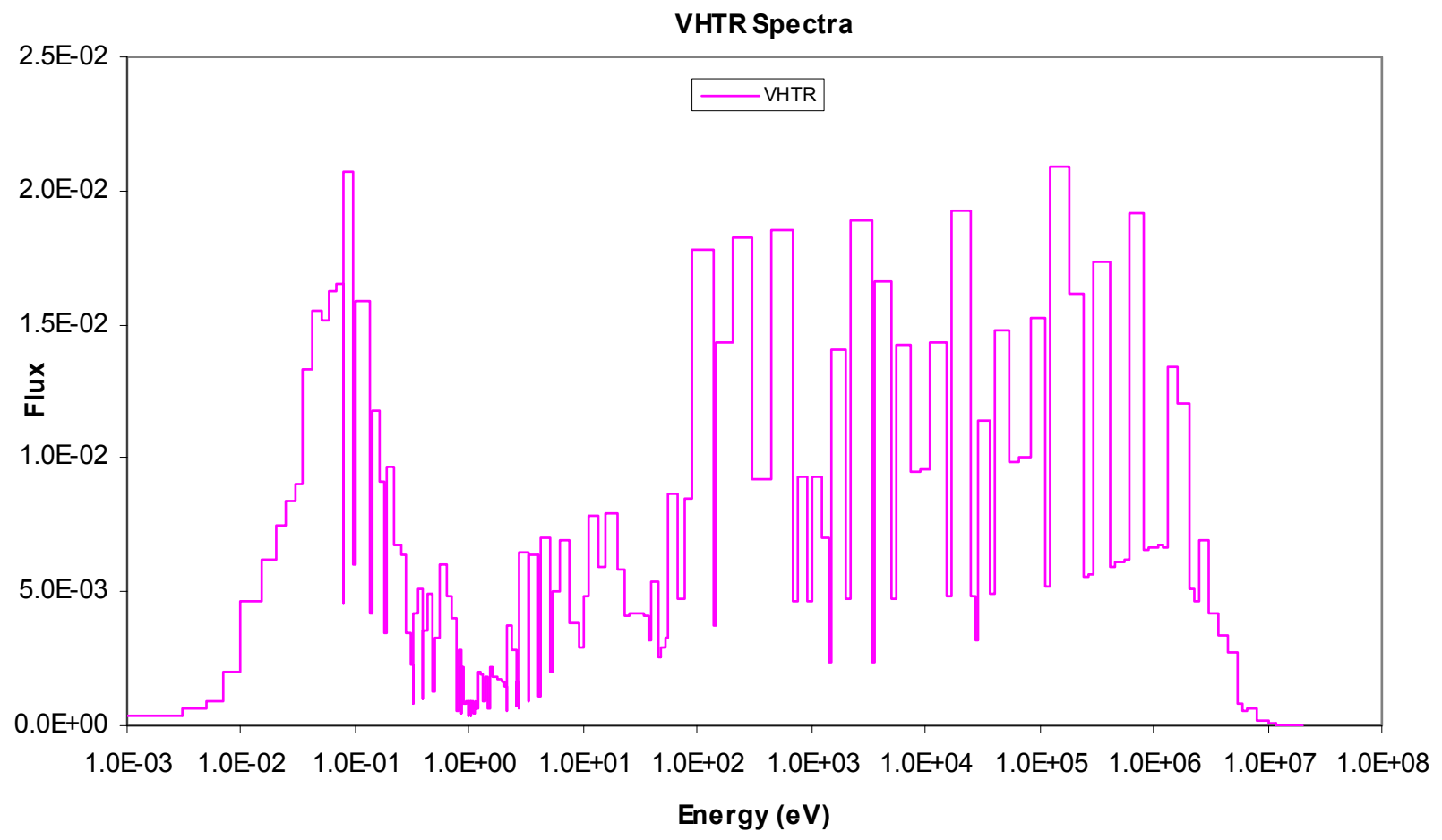

Figure 9: 172-group VHTR/Uranium Spectra

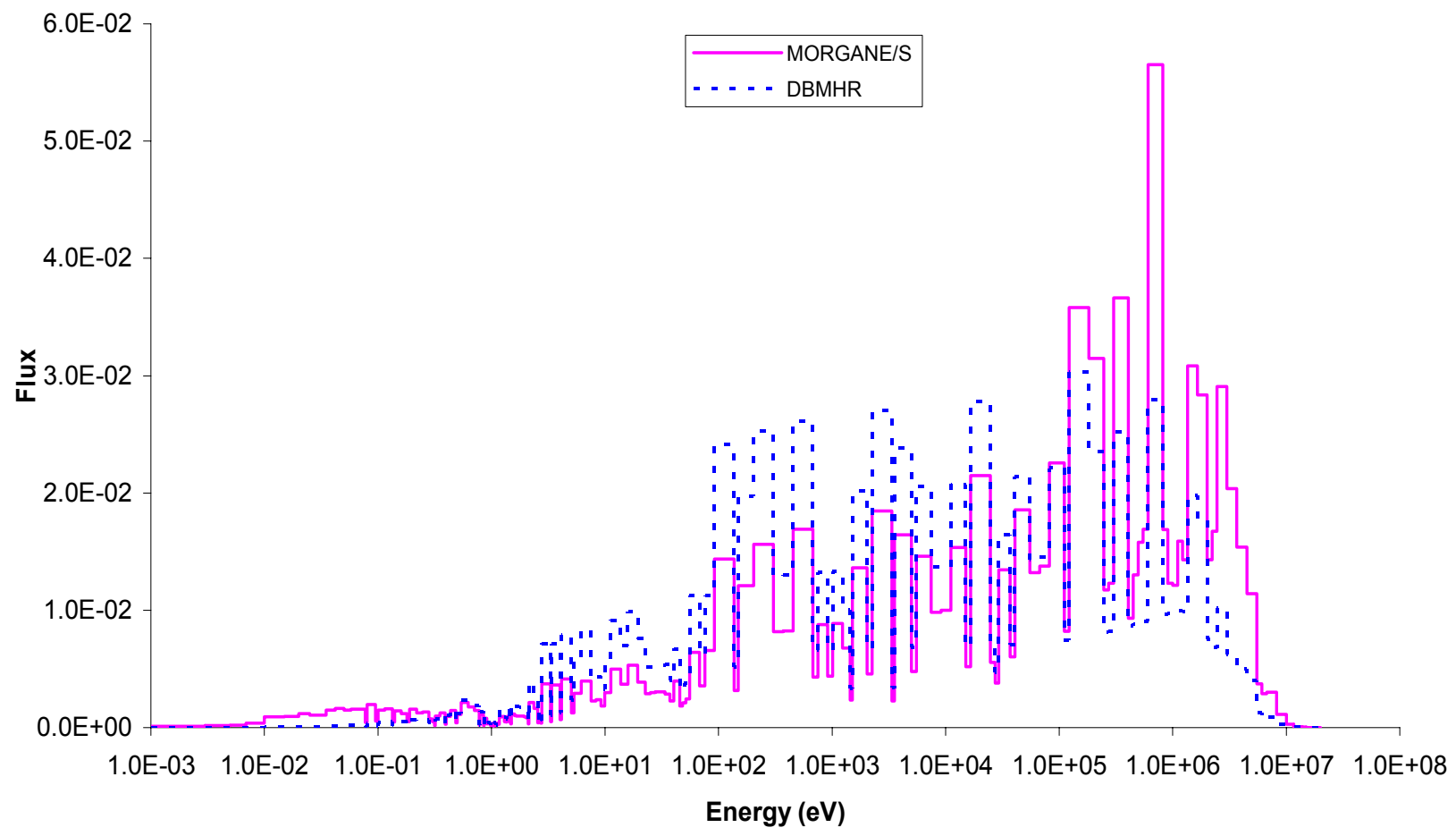

Figure 10: Comparison of 172-group MORGANE/S and DBMHR Spectra 
The comparison of MORGANE/S and DBMHR spectra is shown in Figure 10. In both spectra the thermal flux is very low. Compared with the DBMHR spectrum, the fast flux in the MORGANE/S spectrum is higher but the lower range of the epithermal flux is lower. (Note that the total flux is normalized to 1.0 in the figures). The comparison of the spectral composition is shown in Table 7. It can be seen that in the energy range greater than $110 \mathrm{keV}$, the MORGANE/S flux is apparently higher than that of VHTR/DBMHR, which means that MORGANE/S spectra is harder. This should be due to the small volume ratio between moderator and fuel in the MORGANE/S configuration. The MORGANE/R configuration will be analyzed in 2007. The MORGANE/R configuration has a higher moderation ratio than the MORGANE/S configuration which creates a softer but still epithermal spectrum. It appears that this spectrum may better match the VHTR spectra.

\begin{tabular}{|c|c|c|c|c|c|c|}
\hline \multicolumn{7}{|c|}{ Table 7: } \\
\hline \multirow{2}{*}{ Energy Range } & \multicolumn{3}{|c|}{ MINERVE Reactor } & \multicolumn{2}{c|}{ VHTR } \\
\cline { 2 - 7 } & R1-UO2 & R2-UO2 & R1-MOX & MORGANE/S & Uranium & DBMHR \\
\hline$<1 \mathrm{eV}$ & 0.2045 & 0.3645 & 0.1232 & 0.0444 & 0.2851 & 0.0240 \\
\hline $1-10 \mathrm{eV}$ & 0.0598 & 0.0620 & 0.0638 & 0.0467 & 0.0845 & 0.0856 \\
\hline $10 \mathrm{eV}-1 \mathrm{keV}$ & 0.1408 & 0.1281 & 0.1561 & 0.1607 & 0.2021 & 0.2687 \\
\hline $1 \mathrm{keV}-110 \mathrm{keV}$ & 0.1823 & 0.1440 & 0.2022 & 0.2515 & 0.2260 & 0.3257 \\
\hline$>110 \mathrm{keV}$ & 0.4125 & 0.3014 & 0.4548 & 0.4967 & 0.2023 & 0.2960 \\
\hline Total & 1.0 & 1.0 & 1.0 & 1.0 & 1.0 & 1.0 \\
\hline
\end{tabular}

\subsection{Planned activities for 2007}

Several activities related to reactor modeling are planned for FY07. Pre-analysis estimates of the reactivity effect of the OSMOSE samples in the MORGANE/R, MORGANE/S, and R2-UO2 core configurations will be performed. Additionally, the results of the OSMOSE samples in the R1-UO2 and R1-MOX configurations will be studied and re-analyzed as the results of the chemical analysis become available.

The main goal of reactor modeling efforts in 2007 will be to finalize the models for the R1-UO2 and R1-MOX configurations and to prepare a benchmark report for these configurations and experimental results.

Studies will be performed of the OSMOSE samples in the planned core configurations to determine the relevance of these configurations for the Generation-IV program. Specifically, the configurations will be compared to block-type VHTR and GCR systems. Initial spectra were obtained and compared in 2006. However, a more detailed assessment will be performed in 2007.

\subsection{Issues and concerns}

There are no issues or concerns at this time. 


\section{SAMPLE FABRICATION}

\subsection{Objectives}

The OSMOSE program requires the fabrication of 21 oxide samples containing separated actinides $\left({ }^{232} \mathrm{Th},{ }^{233} \mathrm{U},{ }^{234} \mathrm{U},{ }^{235} \mathrm{U},{ }^{236} \mathrm{U},{ }^{238} \mathrm{U},{ }^{237} \mathrm{~Np},{ }^{238} \mathrm{Pu}^{, 239} \mathrm{Pu}^{, 240} \mathrm{Pu}^{, 241} \mathrm{Pu}^{, 242} \mathrm{Pu},{ }^{241}, 243 \mathrm{Am}\right.$ and ${ }^{244} \mathrm{Cm},{ }^{245} \mathrm{Cm}$ ). The samples consist of assembled fuel pellets containing the isotopes of interest and a double zircaloy cladding. Specifications for the samples include: the pellet size, the pellet density, the homogeneity of the distribution of the actinides inside the UO2 matrix, and the minimization of contamination during the fabrication process.

\subsection{Technical status}

The sample fabrication task is divided into several different activities including: supply and preparation of isotopes, pellet fabrication, cladding and welding, and chemical analysis. Progress in each area is described separately below.

\subsubsection{Supply and preparation of isotopes}

The last material to prepare was the ${ }^{233} \mathrm{U}$. CEA-Valrho was able to locate a small amount of ${ }^{233} \mathrm{U}$ without ${ }^{232} \mathrm{U}$ and others decay products. Therefore, the material was able to be easily purified and processed in a glove box. All of the remaining isotopes are now ready for pellet fabrication.

\subsubsection{Pellet fabrication}

The second set of pellets is composed of 6 samples: $\mathrm{UO}_{2}+{ }^{238} \mathrm{PuO}_{2} ; \mathrm{UO}_{2}+{ }^{240} \mathrm{PuO}_{2} ; \mathrm{UO}_{2}+$ ${ }^{241} \mathrm{PuO}_{2} ; \mathrm{UO}_{2}+{ }^{241} \mathrm{AmO}_{2}(1) ; \mathrm{UO}_{2}+{ }^{241} \mathrm{AmO}_{2}(2)$ and $\mathrm{ThO}_{2}$

Table 8 summarizes the main characteristics of the second set of samples. Good agreement with the specifications was obtained, however the mean density of several samples appears a little low. The diameter is close to the target value. Grinding of the pellets is not allowed to avoid pollution between the samples and the pellet diameter dimension has to be reached exclusively by the process.

\begin{tabular}{|c|c|c|c|c|}
\hline \multicolumn{5}{|c|}{ Table 8: } \\
Setrology of the second set of pellets \\
\hline & $\begin{array}{c}\text { Target } \\
\text { composition } \\
(\mathrm{g})\end{array}$ & $\begin{array}{c}\text { Mean } \\
\text { density } \\
\text { (\% of T.D. })\end{array}$ & $\begin{array}{c}\text { mean } \varnothing \\
(\mathrm{mm})\end{array}$ & $\begin{array}{c}\mathrm{D} \varnothing \\
(\mathrm{mm})\end{array}$ \\
\hline $\mathrm{UO}_{2-}{ }^{238} \mathrm{Pu}$ & 0.4 & 92.0 & 8.16 & 0.09 \\
\hline $\mathrm{UO}_{2-}{ }^{240} \mathrm{Pu}$ & 0.15 & 97.4 & 8.10 & 0.04 \\
\hline $\mathrm{UO}_{2-}{ }^{241} \mathrm{Am}$ & 0.06 & 94.7 & 8.14 & 0.13 \\
\hline $\mathrm{UO}_{2}{ }^{241} \mathrm{Am}$ & 0.2 & 92.6 & 8.14 & 0.18 \\
\hline $\mathrm{ThO}_{2}$ & pure & 92.7 & 8.15 & 0.08 \\
\hline $\mathrm{UO}_{2-}{ }^{241} \mathrm{Pu}$ & $0.1<\mathrm{TC}<0.3$ & 94.0 & 8.10 & 0.15 \\
\hline Specification & & $>95 \%$ & $8.0<\varnothing<8.2$ & $\mathrm{D} \varnothing<0.1$ \\
\hline
\end{tabular}


The OSMOSE furnace and the tri-part (shell) uniaxial press have continued to work flawlessly and there were no problems during the preparation of the third batch of samples. A new press (of the same type) was prepared which will be installed in a hot cell of the C10 line (which is a facility in ATALANTE dedicated to the studies of material with neutron activity). This equipment will be used to prepare the two last samples with up to $4 \%$ of $\mathrm{CmO}_{2}$.

Several discussions were held and it was decided not to sinter the pellets with curium isotopes because of the lack of radioprotection of the OSMOSE furnace. Green pellets for two samples $\left({ }^{244} \mathrm{Cm}\right.$ and ${ }^{244+245} \mathrm{Cm}$ doped compound) and a set of Uranium oxide for calibration will be fabricated.

The third and last set of OSMOSE samples is being prepared. This set includes ${ }^{243} \mathrm{Am}(2$ samples with different concentrations) and ${ }^{233} \mathrm{U}$ prepared in a glove box, and ${ }^{244} \mathrm{Cm},{ }^{244+245} \mathrm{Cm}$, and natural $\mathrm{UO}_{2}$ (green - or unsintered) prepared in a hot cell.

\subsubsection{Cladding and welding}

The same procedure that was followed for the first samples was carried out for the cladding and the welding steps but performed in glove boxes due to the radioactivity of the actinide material.

The sequence followed was one reference sample, three OSMOSE samples, one reference sample, three OSMOSE samples, and one reference sample.

After each welding (of the inner and outer cladding), a leak test was performed. In addition, metallographic inspections were undertaken on the reference samples.

After the acceptance of the 6 sample pins by CEA-Cadarache, the samples were delivered to MINERVE at the end of March using a CROFT container.

\subsubsection{Chemical analysis}

The isotopic and chemical characterization of the doped actinides has been performed for the remaining actinides. At the present time only ${ }^{243} \mathrm{Am}$ and ${ }^{233} \mathrm{U}$ are still waiting to be analyzed by mass spectrometry techniques (IDMS) due to several problems in mass spectrometry laboratory. The analysis should be completed in October.

The analysis of the pellets from the first batch of samples has been completed. The results do not show any important values far from the target values which means that the manufacturing was performed without pollution or cross-contamination of the samples. The final report on the chemical analysis will be completed in October. The analysis of the second set of samples has begun and should be completed by December 2006.

\subsection{Planned activities for 2007}

The last 5 samples - Cm-244, Cm-244+245, Am-243 (x 2) and U-233 - will be fabricated and shipped to CEA-Cadarache inside the RD15IIB container in 2007. The shipment of these 
OSMOSE samples from CEA-Valrho to CEA-Cadarache is a major issue because of the high activity of the Curium samples. Thus, CEA-Cadarache has to obtain special authorization to ship the OSMOSE samples. This authorization is expected in November.

The new challenge will be to perform the cladding and the welding operations in hot cells. Special devices have been already designed to introduce by remote handling the green pellets into the inner core of the clad without damage. The welding station in hot cell is similar to glove box installation and the same parameters will be used. Therefore, no problems are expected for theses operations because of the previous experience with the prior samples.

After shipment to the MINERVE facility at CEA-Cadarache, the samples have to be transferred from the hot cell of the MINERVE facility to the reactor for measurements. For the Curium samples, this requires a new neutron shielded container. The fabrication of this new container and the associated safety authorization were started by CEA Cadarache in the middle of 2006. Authorization and fabrication are expected before June 2007.

In November, 2005, a meeting at ANL was held to prepare the shipping of OSMOSE samples for cross analysis. The samples were originally scheduled for delivery to ANL by February 2006 so that the analysis could be completed in FY2006. Unfortunately, shipping of the samples has been hampered by the numerous difficulties in getting approval from the Safety Authorities in France. The current expectation is that the samples (20 sample pellets from seven samples) will be shipped by December 2006.

\subsection{Issues and Concerns}

The primary issue for the chemical analysis has been getting the approval from the French safety authorities for shipping samples to the U.S. so that the cross-analysis can be performed. Because of the significant delay, this continues to be the major issue with respect to sample analysis. Current plans for FY07 require that the samples are shipped during the first quarter so that the analysis of the samples can be completed in FY07. If they continue to be delayed, the ultimate result will be a delay in program because of the inability to finalize the experimental results because of the uncertainty on the sample compositions.

\section{EXPERIMENTS}

\subsection{Objectives}

The main objective of the OSMOSE measurement program is to provide an experimental database of reactivity-worth measurements in different neutron spectra for the heavy nuclides. This database can then be used as a benchmark for integral reactivity-worth measurements to verify and validate reactor analysis codes. Measurements on other samples will provide additional data for benchmarking depletion codes as well as reactor analysis codes (French codes and U.S. codes). 


\subsection{Technical Status}

The OSMOSE program in the MINERVE facility began in July 2005 in the R1-UO2 core configuration. The experiments went on until June 2006, in parallel with the measurements for the OCEAN program. The OCEAN program is similar to OSMOSE except it is based on samples containing absorber materials.

Over the course of the fiscal year, several series of measurements have been performed. From October 2005 to December 2006, oscillation measurements were conducted in the R1-UO2 configuration using the first set of OSMOSE samples (Pu-239, Pu-242, U/Th-232, U-234, URE, Np-237 (2 samples), Unat).

In March 2006, the second set of samples (Pu-240, Pu-238, Am-241 (2 samples), Pu-241 and pure Th-232) was shipped from CEA Marcoule to CEA Cadarache. In addition, modified conversion ratio measurements in the R1-UO2 core configuration were performed.

From April 2006 to June 2006, oscillation measurements in the R1-UO2 core configuration were performed using the second set of OSMOSE samples. This completed the measurements in the R1-UO2 configuration with all of the OSMOSE samples that are currently available.

Upon completion of the measurements in the R1-UO2 configuration, the core was reloaded with the R1-MOX configuration in July 2006. In August, safety measurements and calibration of the pilot rod in the R1-MOX core configuration were completed. In September, oscillation measurements of the OSMOSE samples and calibration samples began in the R1-MOX core configuration.

The following sections describe the experimental results that were obtained.

\subsubsection{Oscillation measurements of the first set of OSMOSE samples in the R1-UO2 core configuration}

For this first phase of experiments, two series of calibration samples were used. One contained a $\mathrm{UO}_{2}$ matrix with different uranium enrichments (natural, $0.25 \%, 0.5 \%, 0.72 \%, 1 \%, 2 \%, 3 \%, 4 \%$ and $\left.4.95 \% \mathrm{U}^{235}\right)$ and the other contained a $\mathrm{UO}_{2}$ matrix $(0.25 \%$ or $0.53 \%$ enriched in $\mathrm{U}-235)$ with a range of boron concentrations $(0,60,150,333,419$, and $1062 \mathrm{ppm})$. Figure 11 and Figure 12 show the calibration curves obtained in the R1-UO2 configuration. Table 9 and Table 10 show the raw data for the oscillation of the calibration samples.

The reactivity worth of the calibration samples is obtained by deterministic calculations with an accuracy of approximately $1 \%$. The reactivity worth of every sample that is oscillated in MINERVE can be determined by comparing the response to the response from the calibration samples. Samples with a positive reactivity effect are compared to ${ }^{235} \mathrm{U}$ calibration samples, and samples with negative reactivity effects are compared to boron calibration samples. The total uncertainty on the calibration measurements, including material balance of the samples, reproducibility of the measurement, and uncertainty on the reactivity worth calculation, is about $2 \%$. 


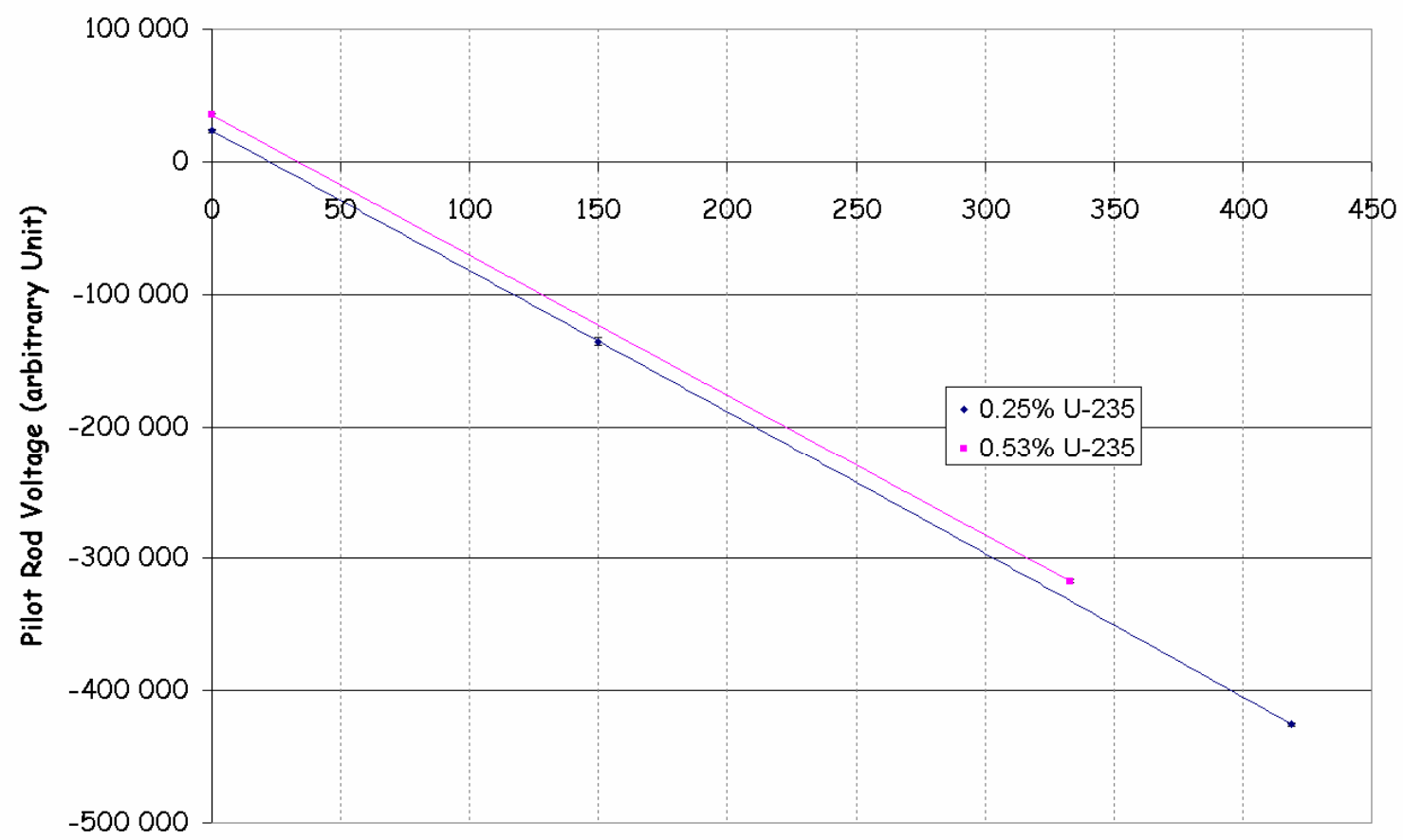

Boron Ratio (ppm)

Figure 11: Calibration curve for boron loaded samples in the R1-UO2 configuration

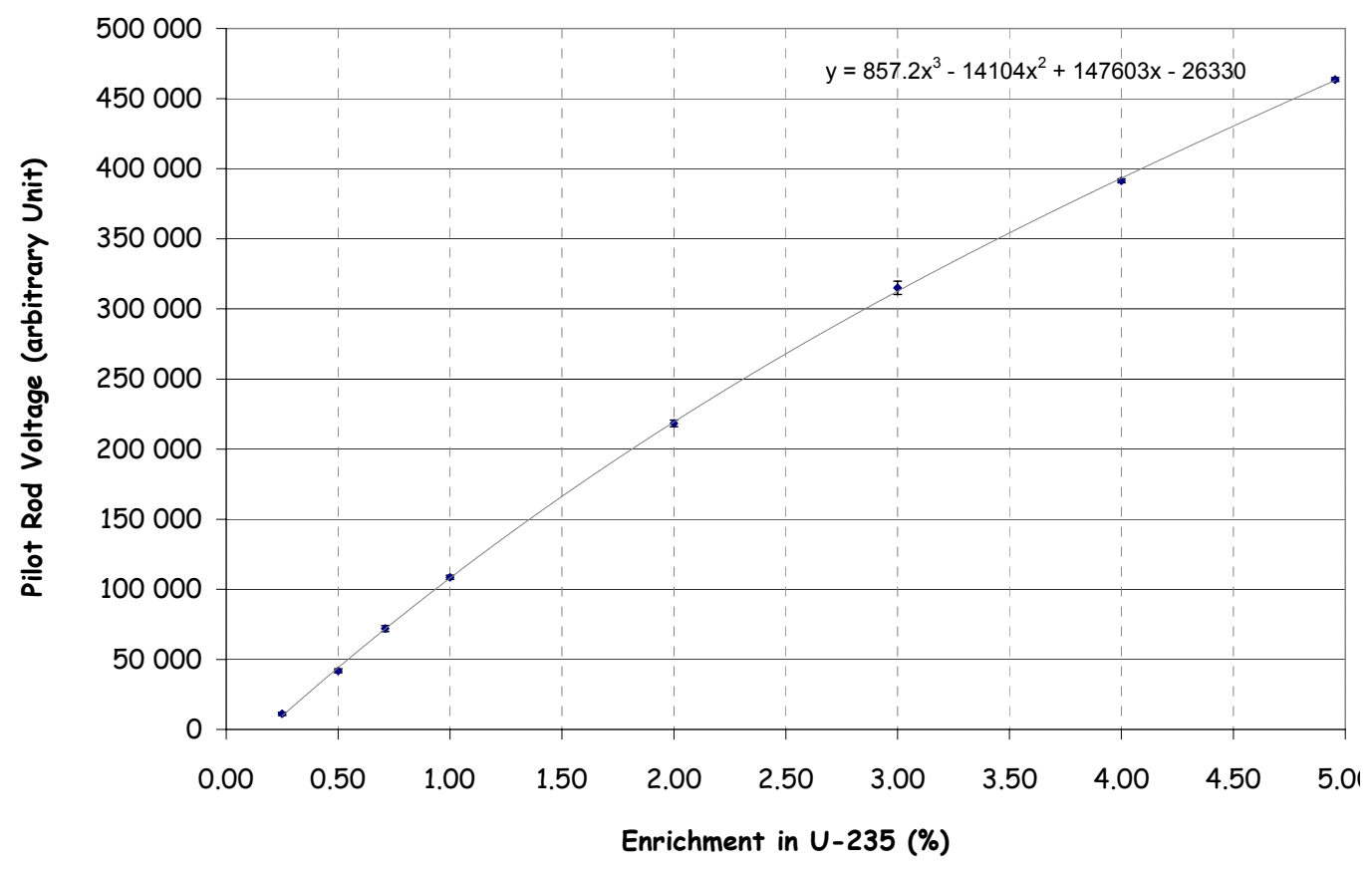

Figure 12: Calibration curve for ${ }^{235} \mathrm{U}$ calibration samples in the R1-UO2 configuration 


\begin{tabular}{|c|c|c|c|}
\hline \multicolumn{4}{|c|}{$\begin{array}{c}\text { Table } 9 \\
\text { Raw data for the borated calibration samples }\end{array}$} \\
\hline Name & $\begin{array}{c}\text { Measurement } \\
\text { date }\end{array}$ & $\begin{array}{c}\text { Signal } \\
\text { (arbitrary unit) }\end{array}$ & $\begin{array}{c}\text { s.d. } \\
\text { (arbitrary unit) }\end{array}$ \\
\hline $\begin{array}{l}7(0 \mathrm{ppm}) \\
7(0 \mathrm{ppm}) \\
7(0 \mathrm{ppm}) \\
7(0 \mathrm{ppm}) \\
7(0 \mathrm{ppm})\end{array}$ & $\begin{array}{c}07 / 28 / 2005 \\
07 / 29 / 2005 \\
08 / 04 / 2005 \\
08 / 05 / 2005 \\
08 / 11 / 2005 \\
\text { Average }\end{array}$ & $\begin{array}{l}23363 \\
21917 \\
22657 \\
22981 \\
25269 \\
\\
23237 \\
\end{array}$ & $\begin{array}{l}3180 \\
2893 \\
1755 \\
2019 \\
1576 \\
\\
1430 \\
\end{array}$ \\
\hline $\begin{array}{l}9(150 \mathrm{ppm}) \\
9(150 \mathrm{ppm}) \\
9(150 \mathrm{ppm}) \\
9(150 \mathrm{ppm}) \\
9(150 \mathrm{ppm}) \\
9(150 \mathrm{ppm}) \\
9(150 \mathrm{ppm}) \\
9(150 \mathrm{ppm})\end{array}$ & $\begin{array}{c}07 / 27 / 2005 \\
07 / 29 / 2005 \\
08 / 03 / 2005 \\
08 / 05 / 2005 \\
08 / 10 / 2005 \\
08 / 12 / 2005 \\
11 / 22 / 2005 \\
11 / 23 / 2005 \\
\text { Average }\end{array}$ & $\begin{array}{l}-133270 \\
-134666 \\
-132646 \\
-137751 \\
-135761 \\
-139832 \\
-132943 \\
-137166 \\
-135504\end{array}$ & $\begin{array}{l}2323 \\
2082 \\
2050 \\
2560 \\
2802 \\
1692 \\
2840 \\
1140 \\
2592\end{array}$ \\
\hline $\begin{array}{l}10(419 \mathrm{ppm}) \\
10(419 \mathrm{ppm}) \\
10(419 \mathrm{ppm}) \\
10(419 \mathrm{ppm}) \\
10(419 \mathrm{ppm}) \\
10(419 \mathrm{ppm}) \\
10(419 \mathrm{ppm})\end{array}$ & $\begin{array}{c}06 / 27 / 2005 \\
06 / 30 / 2005 \\
07 / 20 / 2005 \\
07 / 21 / 2005 \\
07 / 25 / 2005 \\
08 / 12 / 2005 \\
\text { Average }\end{array}$ & $\begin{array}{l}-427891 \\
-425523 \\
-425187 \\
-426829 \\
-425550 \\
-423287 \\
-425711 \\
\end{array}$ & $\begin{array}{l}2644 \\
2940 \\
1158 \\
2576 \\
3288 \\
1787 \\
\\
1306 \\
\end{array}$ \\
\hline $\begin{array}{l}33(333 \mathrm{ppm}) \\
33(333 \mathrm{ppm}) \\
33(333 \mathrm{ppm}) \\
33(333 \mathrm{ppm}) \\
33(333 \mathrm{ppm})\end{array}$ & $\begin{array}{c}07 / 01 / 2005 \\
07 / 19 / 2005 \\
07 / 21 / 2005 \\
07 / 22 / 2005 \\
07 / 26 / 2005 \\
\text { Average }\end{array}$ & $\begin{array}{l}-315814 \\
-316623 \\
-318730 \\
-316052 \\
-318651 \\
-317174\end{array}$ & $\begin{array}{l}1083 \\
3522 \\
3654 \\
1815 \\
2659 \\
1430\end{array}$ \\
\hline $\begin{array}{l}32(0 \mathrm{ppm}) \\
32(0 \mathrm{ppm}) \\
32(0 \mathrm{ppm}) \\
32(0 \mathrm{ppm}) \\
32(0 \mathrm{ppm}) \\
32(0 \mathrm{ppm})\end{array}$ & $\begin{array}{c}06 / 30 / 2005 \\
07 / 06 / 2005 \\
07 / 20 / 2005 \\
07 / 22 / 2005 \\
07 / 27 / 2005 \\
07 / 28 / 2005 \\
\text { Average }\end{array}$ & $\begin{array}{l}35151 \\
34325 \\
35505 \\
34642 \\
37563 \\
34655 \\
\\
35307\end{array}$ & $\begin{array}{l}1968 \\
1848 \\
2916 \\
3516 \\
1929 \\
2374 \\
\\
1306\end{array}$ \\
\hline
\end{tabular}




\begin{tabular}{|c|c|c|c|}
\hline Name & $\begin{array}{c}\text { Measurement } \\
\text { date }\end{array}$ & $\begin{array}{c}\text { Signal } \\
\text { (arbitrary unit) }\end{array}$ & $\begin{array}{c}\text { s.d. } \\
\text { (arbitrary unit) }\end{array}$ \\
\hline $\begin{array}{l}\text { H1 }(0.25 \% \text { U-235) } \\
\text { H1 }(0.25 \% \text { U-235) } \\
\text { H1 }(0.25 \% \text { U-235) } \\
\text { H1 }(0.25 \% \text { U-235) } \\
\text { H1 }(0.25 \% \text { U-235) } \\
\text { H1 }(0.25 \% \text { U-235) } \\
\text { H1 }(0.25 \% \text { U-235) }\end{array}$ & $\begin{array}{l}06 / 29 / 2005 \\
07 / 01 / 2005 \\
07 / 21 / 2005 \\
07 / 26 / 2005 \\
09 / 12 / 2005 \\
09 / 21 / 2005 \\
09 / 29 / 2005 \\
\text { Average } \\
\end{array}$ & $\begin{array}{c}10910 \\
12046 \\
11260 \\
11021 \\
9628 \\
9653 \\
13365 \\
\\
11126 \\
\end{array}$ & $\begin{array}{l}2002 \\
1774 \\
1942 \\
2557 \\
4036 \\
2877 \\
2315 \\
\\
1209 \\
\end{array}$ \\
\hline $\begin{array}{l}\text { H3 }(0.71 \% \text { U-235) } \\
\text { H3 }(0.71 \% \text { U-235) } \\
\text { H3 }(0.71 \% \text { U-235) } \\
\text { H3 }(0.71 \% \text { U-235) } \\
\text { H3 }(0.71 \% \text { U-235) } \\
\text { H3 }(0.71 \% \text { U-235) } \\
\text { H3 }(0.71 \% \text { U-235) } \\
\text { H3 }(0.71 \% \text { U-235) } \\
\text { H3 }(0.71 \% \text { U-235) }\end{array}$ & $\begin{array}{c}06 / 04 / 2005 \\
06 / 30 / 2005 \\
07 / 19 / 2005 \\
07 / 25 / 2005 \\
07 / 26 / 2005 \\
08 / 23 / 2005 \\
09 / 13 / 2005 \\
09 / 27 / 2005 \\
09 / 29 / 2005 \\
\text { Average }\end{array}$ & $\begin{array}{l}73666 \\
70583 \\
74867 \\
69411 \\
71139 \\
74445 \\
70981 \\
69395 \\
73522 \\
72001\end{array}$ & $\begin{array}{l}2053 \\
1139 \\
1344 \\
2921 \\
2817 \\
1863 \\
3005 \\
2709 \\
3133 \\
\\
\\
2138 \\
\end{array}$ \\
\hline $\begin{array}{l}\text { H5 }(2 \% \text { U-235) } \\
\text { H5 }(2 \% \text { U-235) } \\
\text { H5 (2\% U-235) } \\
\text { H5 (2\% U-235) } \\
\text { H5 (2\% U-235) } \\
\text { H5 (2\% U-235) }\end{array}$ & $\begin{array}{c}06 / 27 / 2005 \\
07 / 01 / 2005 \\
07 / 20 / 2005 \\
07 / 21 / 2005 \\
07 / 25 / 2005 \\
08 / 23 / 2005 \\
\text { Average } \\
\end{array}$ & $\begin{array}{l}220077 \\
215853 \\
221898 \\
218901 \\
216855 \\
216154 \\
\\
218290\end{array}$ & $\begin{array}{l}2309 \\
2381 \\
2531 \\
1561 \\
1915 \\
3927 \\
\\
2414\end{array}$ \\
\hline $\begin{array}{l}\text { H8 (4.955\% U-235) } \\
\text { H8 (4.955\% U-235) } \\
\text { H8 (4.955\% U-235) } \\
\text { H8 (4.955\% U-235) } \\
\text { H8 (4.955\% U-235) }\end{array}$ & $\begin{array}{c}06 / 27 / 2005 \\
07 / 21 / 2005 \\
07 / 22 / 2005 \\
07 / 27 / 2005 \\
08 / 23 / 2005 \\
\text { Average } \\
\end{array}$ & $\begin{array}{l}462406 \\
465982 \\
463511 \\
461220 \\
464946 \\
\\
463613 \\
\end{array}$ & $\begin{array}{l}3661 \\
2224 \\
3078 \\
3814 \\
3489 \\
\\
1430\end{array}$ \\
\hline $\begin{array}{l}\text { H2 }(0.50 \% \text { U-235) } \\
\text { H2 }(0.50 \% \mathrm{U}-235) \\
\text { H2 }(0.50 \% \mathrm{U}-235) \\
\mathrm{H} 2(0.50 \% \mathrm{U}-235) \\
\mathrm{H} 2(0.50 \% \mathrm{U}-235)\end{array}$ & $\begin{array}{c}07 / 27 / 2005 \\
07 / 29 / 2005 \\
08 / 03 / 2005 \\
08 / 05 / 2005 \\
08 / 10 / 2005 \\
\text { Average } \\
\end{array}$ & $\begin{array}{l}43709 \\
41400 \\
43008 \\
40983 \\
40130 \\
41846 \\
\end{array}$ & $\begin{array}{l}3046 \\
2277 \\
2832 \\
1498 \\
1707 \\
\\
\\
1430\end{array}$ \\
\hline $\begin{array}{l}\text { H4 (1\% U-235) } \\
\text { H4 (1\% U-235) } \\
\text { H4 (1\% U-235) } \\
\text { H4 (1\% U-235) } \\
\text { H4 (1\% U-235) }\end{array}$ & $\begin{array}{c}07 / 28 / 2005 \\
08 / 04 / 2005 \\
08 / 05 / 2005 \\
08 / 10 / 2005 \\
08 / 11 / 2005 \\
\text { Average }\end{array}$ & $\begin{array}{l}107509 \\
108518 \\
110913 \\
108062 \\
107719 \\
108544\end{array}$ & $\begin{array}{l}2913 \\
2098 \\
1853 \\
2220 \\
2075 \\
\\
\\
1430\end{array}$ \\
\hline
\end{tabular}




\begin{tabular}{|c|c|c|c|}
\hline \multicolumn{4}{|c|}{ Table 10: Raw data for the U-235 calibration samples } \\
\hline Name & $\begin{array}{c}\text { Measurement } \\
\text { date }\end{array}$ & $\begin{array}{c}\text { Signal } \\
\text { (arbitrary unit) }\end{array}$ & $\begin{array}{c}\text { s.d. } \\
\text { (arbitrary unit) }\end{array}$ \\
\hline H6 (3\% U-235) & $07 / 28 / 2005$ & 315427 & 2246 \\
H6 (3\% U-235) & $08 / 02 / 2005$ & 307077 & 1617 \\
H6 (3\% U-235) & $08 / 04 / 2005$ & 311341 & 2462 \\
H6 (3\% U-235) & $08 / 10 / 2005$ & 315659 & 3474 \\
H6 (3\% U-235) & $08 / 11 / 2005$ & 308138 & 2849 \\
H6 (3\% U-235) & $10 / 07 / 2005$ & 317281 & 2102 \\
H6 (3\% U-235) & $10 / 12 / 2005$ & 320075 & 1281 \\
H6 (3\% U-235) & $10 / 19 / 2005$ & 316386 & 2364 \\
H6 (3\% U-235) & $11 / 08 / 2005$ & 321127 & 1064 \\
H6 (3\% U-235) & $11 / 10 / 2005$ & 317613 & 1393 \\
& & & 4727 \\
\hline H7 (4\% U-235) & Average & 315012 & 2172 \\
H7 (4\% U-235) & $08 / 02 / 2005$ & 391765 & 3645 \\
H7 (4\% U-235) & $08 / 05 / 2005$ & 389653 & 3020 \\
H7 (4\% U-235) & $08 / 11 / 2005$ & 390952 & 3171 \\
H7 (4\% U-235) & $08 / 23 / 2005$ & 393952 & 4490 \\
& & 390471 & 1430 \\
\hline
\end{tabular}

The oscillation of the first set of OSMOSE samples was performed between September and December 2005. Each of the 8 samples was oscillated 5 or 6 times inside the R1-UO2 configuration. A cycle length of 120 seconds was selected with a measurement consists of 10 cycles. Table 11 shows the results of the oscillation measurements.

\begin{tabular}{|c|c|c|c|}
\hline \multicolumn{4}{|c|}{ Table 11: Raw data for the OSMOSE samples } \\
\hline & $\begin{array}{c}\text { Measurement } \\
\text { date }\end{array}$ & $\begin{array}{c}\text { Signal } \\
\text { (arbitrary unit) }\end{array}$ & $\begin{array}{c}\text { s.d. } \\
\text { (arbitrary unit) }\end{array}$ \\
\hline Name & $09 / 02 / 2005$ & 19651 & 3715 \\
Uth & $09 / 08 / 2005$ & 20718 & 2551 \\
Uth & $09 / 13 / 2005$ & 19263 & 2616 \\
Uth & $09 / 27 / 2005$ & 21396 & 1758 \\
Uth & $09 / 30 / 2005$ & 21805 & 2741 \\
Uth & & & 1430 \\
& Average & 20567 & 3015 \\
& $09 / 02 / 2005$ & 248906 & 3565 \\
Pu-239 & $09 / 08 / 2005$ & 249808 & 4270 \\
Pu-239 & $09 / 20 / 2005$ & 249474 & 4026 \\
Pu-239 & $09 / 28 / 2005$ & 251513 & 3378 \\
Pu-239 & $09 / 30 / 2005$ & 250436 & 1430 \\
\hline
\end{tabular}




\begin{tabular}{|c|c|c|c|}
\hline Name & $\begin{array}{c}\text { Measurement } \\
\text { date }\end{array}$ & $\begin{array}{c}\text { Signal } \\
\text { (arbitrary unit) }\end{array}$ & $\begin{array}{c}\text { s.d. } \\
\text { (arbitrary unit) }\end{array}$ \\
\hline $\begin{array}{l}\text { Unat } \\
\text { Unat } \\
\text { Unat } \\
\text { Unat } \\
\text { Unat } \\
\text { Unat } \\
\text { Unat }\end{array}$ & $\begin{array}{c}09 / 08 / 2005 \\
09 / 13 / 2005 \\
09 / 27 / 2005 \\
09 / 30 / 2005 \\
10 / 04 / 2005 \\
10 / 05 / 2005 \\
10 / 05 / 2005 \\
\text { Average }\end{array}$ & $\begin{array}{l}57457 \\
62721 \\
64764 \\
63749 \\
62191 \\
63142 \\
63081 \\
\\
62444\end{array}$ & $\begin{array}{l}2003 \\
2334 \\
2156 \\
3091 \\
2041 \\
1826 \\
1445 \\
\\
2345\end{array}$ \\
\hline $\begin{array}{l}\text { URE } \\
\text { URE } \\
\text { URE } \\
\text { URE } \\
\text { URE }\end{array}$ & $\begin{array}{c}09 / 19 / 2005 \\
09 / 20 / 2005 \\
09 / 29 / 2005 \\
10 / 04 / 2005 \\
10 / 05 / 2005 \\
\text { Average }\end{array}$ & $\begin{array}{l}360563 \\
358203 \\
358650 \\
361587 \\
362274 \\
360256\end{array}$ & $\begin{array}{l}1851 \\
3277 \\
2015 \\
1484 \\
1025 \\
1430\end{array}$ \\
\hline $\begin{array}{l}\mathrm{Pu}-242 \\
\mathrm{Pu}-242 \\
\mathrm{Pu}-242 \\
\mathrm{Pu}-242 \\
\mathrm{Pu}-242\end{array}$ & $\begin{array}{c}09 / 06 / 2005 \\
09 / 08 / 2005 \\
09 / 20 / 2005 \\
09 / 28 / 2005 \\
09 / 30 / 2005 \\
\text { Average }\end{array}$ & $\begin{array}{l}-1793 \\
-3308 \\
-2890 \\
-2837 \\
-3178 \\
-2801 \\
\end{array}$ & $\begin{array}{l}2333 \\
2631 \\
2088 \\
1710 \\
2236 \\
\\
1430\end{array}$ \\
\hline $\begin{array}{l}\text { U-234 } \\
\text { U-234 } \\
\text { U-234 } \\
\text { U-234 } \\
\text { U-234 }\end{array}$ & $\begin{array}{c}09 / 06 / 2005 \\
09 / 12 / 2005 \\
09 / 21 / 2005 \\
09 / 29 / 2005 \\
10 / 04 / 2005 \\
\text { Average }\end{array}$ & $\begin{array}{l}-5564 \\
-5885 \\
-4398 \\
-6361 \\
-4505 \\
-5343 \\
\end{array}$ & $\begin{array}{l}3246 \\
2115 \\
2439 \\
2874 \\
1968 \\
\\
\\
1430 \\
\end{array}$ \\
\hline $\begin{array}{l}\text { Np237/1 } \\
\text { Np237/1 } \\
\text { Np237/1 } \\
\text { Np237/1 } \\
\text { Np237/1 }\end{array}$ & $\begin{array}{c}11 / 22 / 2005 \\
11 / 23 / 2005 \\
11 / 23 / 2005 \\
11 / 24 / 2005 \\
11 / 24 / 2005 \\
\text { Average } \\
\end{array}$ & $\begin{array}{l}12757 \\
12462 \\
10815 \\
11150 \\
11450 \\
\\
11727 \\
\end{array}$ & $\begin{array}{l}1446 \\
1404 \\
1286 \\
2899 \\
2697 \\
\\
1430 \\
\end{array}$ \\
\hline $\begin{array}{l}\text { Np237/2 } \\
\text { Np237/2 } \\
\text { Np237/2 } \\
\text { Np237/2 } \\
\text { Np237/2 } \\
\text { Np237/2 }\end{array}$ & $\begin{array}{c}11 / 22 / 2005 \\
11 / 23 / 2005 \\
11 / 23 / 2005 \\
11 / 24 / 2005 \\
11 / 24 / 2005 \\
12 / 01 / 2005 \\
\text { Average }\end{array}$ & $\begin{array}{l}-207188 \\
-211771 \\
-213335 \\
-212343 \\
-210584 \\
-211570 \\
-211132\end{array}$ & $\begin{array}{l}2809 \\
1165 \\
1674 \\
1391 \\
1868 \\
1917 \\
\\
\\
2134\end{array}$ \\
\hline
\end{tabular}




\subsubsection{Oscillation measurements of the second set of OSMOSE samples in the R1-UO2 core configuration}

For this phase of experiments, the same two series of calibration samples were used as those in section 5.2.1.

In addition, a new series of borated calibration samples, fabricated especially for the OCEAN and the OSMOSE programs was also oscillated in October in the R1-UO2 configuration. The new borated samples are made of a natural $\mathrm{UO}_{2}$ matrix with a range of boron concentrations from 55 to $400 \mathrm{pcm}(55.5,158,231,336$, and $400 \mathrm{ppm})$. These samples were fabricated to improve the accuracy on the calibration of the signals because there is an improved knowledge of the material balance and specifications of the new calibration samples.

Figure 13 shows the calibration curve obtained in the R1-UO2 configuration with the new borated samples. Table 12 shows the raw data for the oscillation of the new calibration samples.

The oscillation of the second set of OSMOSE samples was performed between April and June 2006. Each one of the 6 samples was oscillated 5 or 6 times inside the R1-UO2 configuration. A cycle length of 120 seconds was selected and a measurement consists of 10 cycles. Table 13 shows the results of the oscillation measurements for the second set of OSMOSE samples.

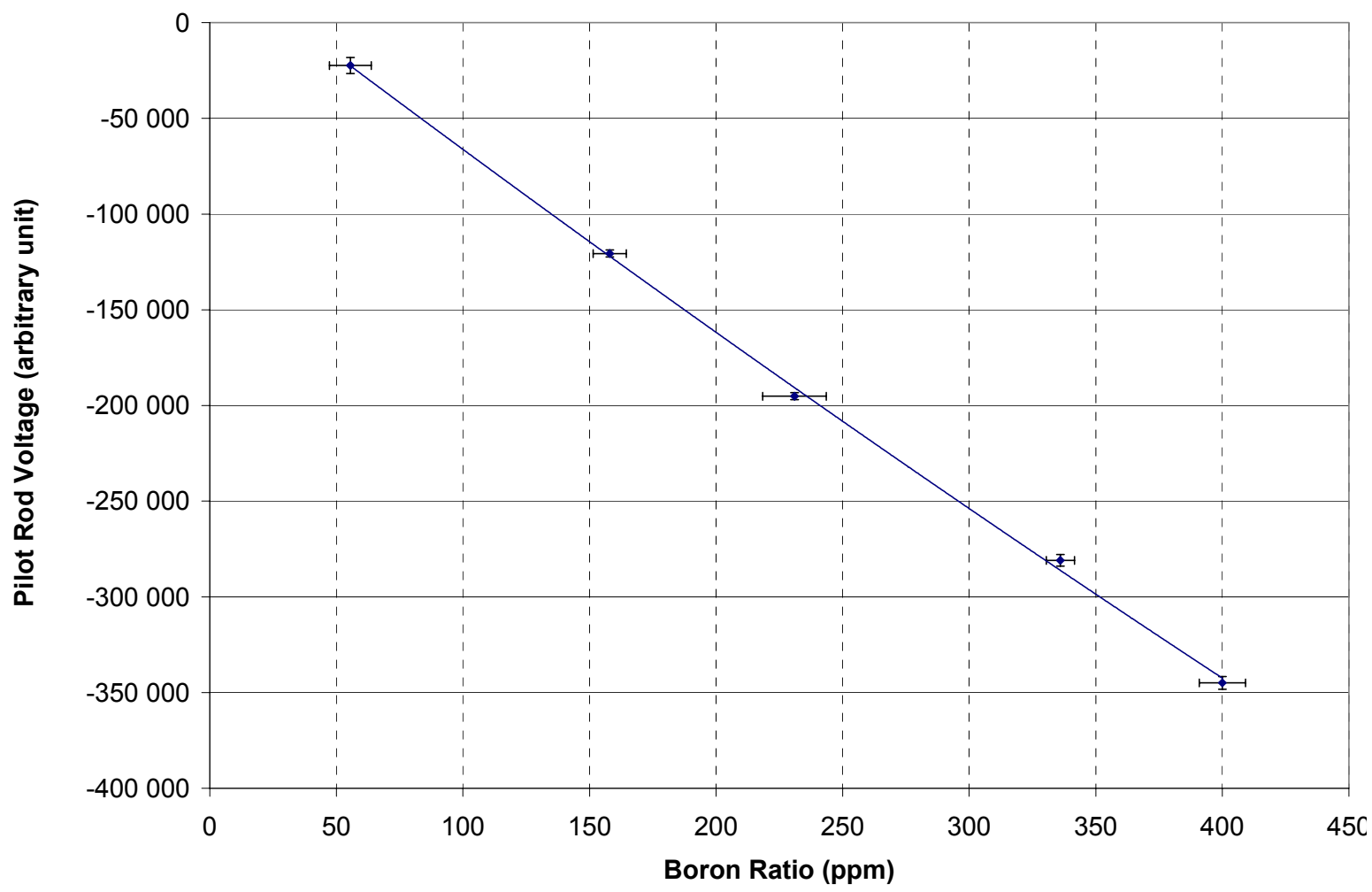

Figure 13: Calibration curve for boron loaded samples in the R1-UO2 configuration of the OSMOSE program 


\begin{tabular}{|c|c|c|c|}
\hline \multicolumn{4}{|c|}{$\begin{array}{c}\text { Table } 12 \\
\text { Raw data for the borated calibration samples }\end{array}$} \\
\hline Name & $\begin{array}{l}\text { Measurement } \\
\text { date }\end{array}$ & $\begin{array}{c}\text { Signal } \\
\text { (arbitrary unit) }\end{array}$ & $\begin{array}{c}\text { s.d. } \\
\text { (arbitrary unit) }\end{array}$ \\
\hline $\begin{array}{l}\text { B500 (400 ppm) } \\
\text { B500 (400 ppm) } \\
\text { B500 (400 ppm) } \\
\text { B500 (400 ppm) } \\
\text { B500 (400 ppm) } \\
\text { B500 (400 ppm) }\end{array}$ & $\begin{array}{c}02 / 07 / 2006 \\
02 / 09 / 2006 \\
02 / 10 / 2006 \\
02 / 14 / 2006 \\
02 / 16 / 2006 \\
02 / 16 / 2006 \\
\text { Average }\end{array}$ & $\begin{array}{l}-339980 \\
-346602 \\
-342278 \\
-345783 \\
-349177 \\
-345829 \\
-344942\end{array}$ & $\begin{array}{l}1833 \\
1685 \\
3270 \\
2042 \\
2144 \\
2135 \\
\\
3283\end{array}$ \\
\hline $\begin{array}{l}\text { B400 (336 ppm) } \\
\text { B400 (336 ppm) } \\
\text { B400 (336 ppm) } \\
\text { B400 (336 ppm) } \\
\text { B400 (336 ppm) } \\
\text { B400 (336 ppm) }\end{array}$ & $\begin{array}{c}02 / 07 / 2006 \\
02 / 08 / 2006 \\
02 / 10 / 2006 \\
02 / 14 / 2006 \\
02 / 15 / 2006 \\
02 / 16 / 2006 \\
\text { Average }\end{array}$ & $\begin{array}{l}-278510 \\
-277174 \\
-282954 \\
-285547 \\
-280661 \\
-280501 \\
-280891 \\
\end{array}$ & $\begin{array}{l}1694 \\
2382 \\
1670 \\
2124 \\
1294 \\
2436 \\
\\
3021 \\
\end{array}$ \\
\hline $\begin{array}{l}\text { B300 (231 ppm) } \\
\text { B300 (231 ppm) } \\
\text { B300 (231 ppm) } \\
\text { B300 (231 ppm) } \\
\text { B300 (231 ppm) }\end{array}$ & $\begin{array}{c}02 / 07 / 2006 \\
02 / 08 / 2006 \\
02 / 09 / 2006 \\
02 / 13 / 2006 \\
02 / 15 / 2006 \\
\text { Average }\end{array}$ & $\begin{array}{l}-196891 \\
-192917 \\
-193946 \\
-197761 \\
-194084 \\
-195120 \\
\end{array}$ & $\begin{array}{l}2738 \\
1319 \\
1629 \\
2133 \\
2250 \\
\\
1791 \\
\end{array}$ \\
\hline $\begin{array}{l}\text { B200 (158 ppm) } \\
\text { B200 (158 ppm) } \\
\text { B200 (158 ppm) } \\
\text { B200 (158 ppm) } \\
\text { B200 (158 ppm) }\end{array}$ & $\begin{array}{c}02 / 07 / 2006 \\
02 / 08 / 2006 \\
02 / 09 / 2006 \\
02 / 13 / 2006 \\
02 / 15 / 2006 \\
\text { Average } \\
\end{array}$ & $\begin{array}{l}-118184 \\
-123520 \\
-120753 \\
-120514 \\
-120071 \\
-120608 \\
\end{array}$ & $\begin{array}{l}1389 \\
3177 \\
2610 \\
3273 \\
1017 \\
1791 \\
\end{array}$ \\
\hline $\begin{array}{l}\mathrm{B} 100(55.5 \mathrm{ppm}) \\
\mathrm{B} 100(55.5 \mathrm{ppm}) \\
\mathrm{B} 100(55.5 \mathrm{ppm}) \\
\mathrm{B} 100(55.5 \mathrm{ppm}) \\
\mathrm{B} 100(55.5 \mathrm{ppm}) \\
\mathrm{B} 100(55.5 \mathrm{ppm})\end{array}$ & $\begin{array}{c}02 / 07 / 2006 \\
02 / 08 / 2006 \\
02 / 09 / 2006 \\
02 / 13 / 2006 \\
02 / 15 / 2006 \\
02 / 16 / 2006 \\
\text { Average }\end{array}$ & $\begin{array}{l}-26349 \\
-19365 \\
-20594 \\
-28950 \\
-19034 \\
-19992 \\
-22381\end{array}$ & $\begin{array}{l}1417 \\
1998 \\
2556 \\
2196 \\
1749 \\
1983 \\
\\
4197 \\
\end{array}$ \\
\hline
\end{tabular}




\begin{tabular}{|c|c|c|c|}
\hline \multicolumn{4}{|c|}{$\begin{array}{c}\text { Table } 13 \\
\text { Raw data for the OSMOSE samples }\end{array}$} \\
\hline Name & $\begin{array}{c}\text { Measurement } \\
\text { Date }\end{array}$ & $\begin{array}{c}\text { Signal } \\
\text { (arbitrary units) }\end{array}$ & $\begin{array}{c}\text { s.d. } \\
\text { (arbitrary units) }\end{array}$ \\
\hline $\begin{array}{l}\text { Pu-238 } \\
\text { Pu-238 } \\
\text { Pu-238 } \\
\text { Pu-238 } \\
\text { Pu-238 }\end{array}$ & $\begin{array}{c}04 / 27 / 2006 \\
05 / 03 / 2006 \\
05 / 05 / 2006 \\
05 / 11 / 2006 \\
05 / 12 / 2006 \\
\text { Average }\end{array}$ & $\begin{array}{l}-144792 \\
-143937 \\
-140090 \\
-142245 \\
-138885 \\
-141990 \\
\end{array}$ & $\begin{array}{l}3876 \\
3752 \\
3967 \\
3283 \\
2942 \\
\\
1791 \\
\end{array}$ \\
\hline $\begin{array}{l}\mathrm{Pu}-240 \\
\mathrm{Pu}-240 \\
\mathrm{Pu}-240 \\
\mathrm{Pu}-240 \\
\mathrm{Pu}-240 \\
\mathrm{Pu}-240\end{array}$ & $\begin{array}{c}04 / 27 / 2006 \\
05 / 03 / 2006 \\
05 / 09 / 2006 \\
05 / 11 / 2006 \\
05 / 19 / 2006 \\
06 / 16 / 2006 \\
\text { Average }\end{array}$ & $\begin{array}{l}-135336 \\
-139927 \\
-135622 \\
-140183 \\
-141534 \\
-137360 \\
-138327 \\
\end{array}$ & $\begin{array}{l}2363 \\
2183 \\
3667 \\
1804 \\
3769 \\
3734 \\
\\
\\
2588 \\
\end{array}$ \\
\hline $\begin{array}{l}\mathrm{Pu}-241 \\
\mathrm{Pu}-241 \\
\mathrm{Pu}-241 \\
\mathrm{Pu}-241 \\
\mathrm{Pu}-241\end{array}$ & $\begin{array}{c}04 / 27 / 2006 \\
05 / 05 / 2006 \\
05 / 09 / 2006 \\
05 / 11 / 2006 \\
05 / 19 / 2006 \\
\text { Average } \\
\end{array}$ & $\begin{array}{l}126400 \\
122235 \\
124459 \\
124892 \\
125847 \\
\\
124766 \\
\end{array}$ & $\begin{array}{l}1033 \\
3697 \\
2139 \\
2465 \\
2747 \\
\\
\\
1791 \\
\end{array}$ \\
\hline $\begin{array}{l}\mathrm{Am} 41 / 1 \\
\mathrm{Am} 41 / 1 \\
\mathrm{Am} 41 / 1 \\
\mathrm{Am} 41 / 1 \\
\mathrm{Am} 41 / 1 \\
\mathrm{Am} 41 / 1\end{array}$ & $\begin{array}{c}04 / 26 / 2006 \\
05 / 03 / 2006 \\
05 / 05 / 2006 \\
05 / 09 / 2006 \\
05 / 12 / 2006 \\
06 / 16 / 2006 \\
\text { Average } \\
\end{array}$ & $\begin{array}{l}-53251 \\
-50484 \\
-49435 \\
-45293 \\
-47621 \\
-52955 \\
\\
-49840 \\
\end{array}$ & $\begin{array}{l}3330 \\
2767 \\
2620 \\
2204 \\
3402 \\
2385 \\
\\
\\
\end{array}$ \\
\hline $\begin{array}{l}\mathrm{Am} 41 / 2 \\
\mathrm{Am} 41 / 2 \\
\mathrm{Am} 41 / 2 \\
\mathrm{Am} 41 / 2 \\
\mathrm{Am} 41 / 2 \\
\mathrm{Am} 41 / 2\end{array}$ & $\begin{array}{c}04 / 26 / 2006 \\
05 / 03 / 2006 \\
05 / 05 / 2006 \\
05 / 09 / 2006 \\
05 / 12 / 2006 \\
06 / 16 / 2006 \\
\text { Average }\end{array}$ & $\begin{array}{l}-258247 \\
-252988 \\
-256829 \\
-247476 \\
-249891 \\
-257324 \\
-253792 \\
\end{array}$ & $\begin{array}{l}1433 \\
3065 \\
2482 \\
2533 \\
2641 \\
2538 \\
\\
\end{array}$ \\
\hline $\begin{array}{l}\text { Th32 } \\
\text { Th32 } \\
\text { Th32 } \\
\text { Th32 } \\
\text { Th32 } \\
\text { Th32 }\end{array}$ & $\begin{array}{c}05 / 05 / 2006 \\
05 / 05 / 2006 \\
05 / 09 / 2006 \\
05 / 12 / 2006 \\
05 / 23 / 2006 \\
05 / 23 / 2006 \\
\text { Average }\end{array}$ & $\begin{array}{l}-275800 \\
-273168 \\
-269435 \\
-269204 \\
-277421 \\
-275954 \\
\end{array}$ & $\begin{array}{l}2772 \\
2810 \\
3541 \\
3296 \\
2463 \\
3028 \\
\\
\\
3515\end{array}$ \\
\hline
\end{tabular}




\subsubsection{Modified conversion ratio measurements in the R1-UO2 configuration}

The measurements were performed using a gamma spectrometry technique applied directly on irradiated fuel pins. The technique is described in reference [6].

The central channel of the R1-UO2 lattice was loaded with the oscillation rod, containing the 'H6' U-235 calibration sample enriched at 3\% in U-235. The modified conversion ratio $\mathrm{C} 8 / \mathrm{F}_{\text {tot, }}$, defined as the ratio of the capture cross section of U-238 to the total fission cross section, was obtained for seven $\mathrm{UO}_{2}$ fuel pins, and for the central ' $\mathrm{H} 6$ ' sample (see positions of the fuel pins in Figure 14).

EST

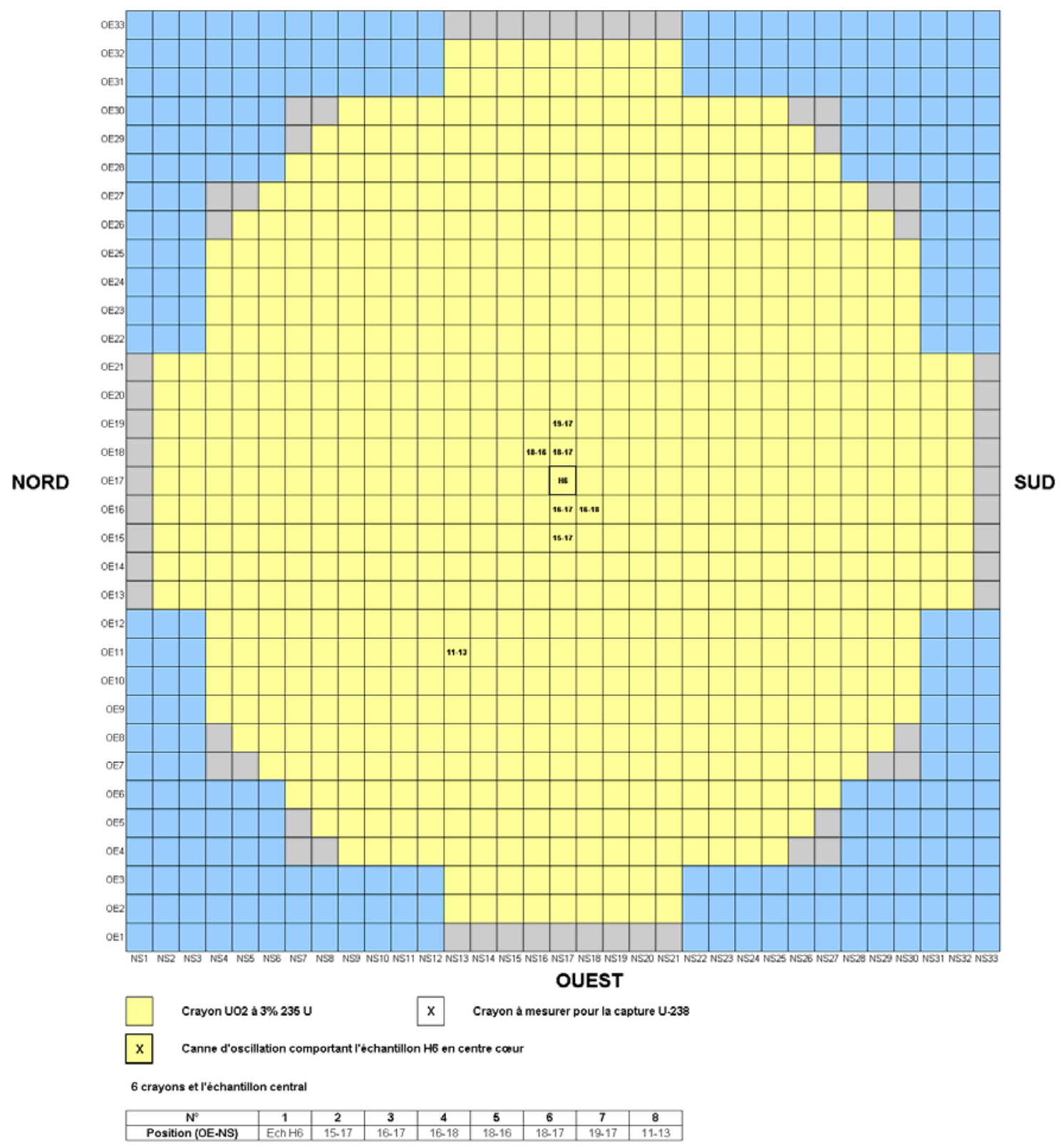

Figure 14: Position of the studied fuel pins and sample in the R1-UO2 lattice 


\begin{tabular}{|c|c|c|}
\hline \multicolumn{3}{|c|}{$\begin{array}{l}\text { Table } 14 \\
\text { Experimental results for the modified conversion ratio } \\
\left(\mathrm{C} 8 / \mathrm{F}_{\text {tot }}\right) \text { measurements }\end{array}$} \\
\hline Fuel pin / sample & $\mathrm{C} 8 / \mathrm{F}_{\text {tot }}$ & s.d. $(\%)$ \\
\hline Fuel pin $15-17$ & 0.503 & $3.5 \%$ \\
\hline Fuel pin $16-17$ & 0.511 & $3.5 \%$ \\
\hline Fuel pin $16-18$ & 0.505 & $3.5 \%$ \\
\hline Fuel pin $18-16$ & 0.508 & $3.5 \%$ \\
\hline Fuel pin $18-17$ & 0.506 & $3.5 \%$ \\
\hline Fuel pin $19-17$ & 0.507 & $3.5 \%$ \\
\hline Fuel pin 11-13 & 0.508 & $3.5 \%$ \\
\hline Sample H6 & 0.493 & $3.5 \%$ \\
\hline
\end{tabular}

The experimental results were obtained as shown in Table 14. An excellent agreement between all fuel pins and samples was obtained. This measurement has to be compared with the calculation results obtained using the same calculation model as the one used for the data analysis of oscillation measurements. A good agreement between calculation and experimental results shall prove the ability of the calculation model to correctly calculate the neutron spectrum.

\subsubsection{Oscillation measurements of the first set of OSMOSE samples in the R1-MOX core configuration}

The ability of the oscillation technique to accurately determine the reactivity-worth of unknown samples relies on the accurate calibration and understanding of the reactivity effects from the operation of the pilot rod. The pilot rod is a servo-driven system that rotates cadmium sections in overlapping patterns to cause a change in the neutron absorption of the pilot rod as a function of the angle of the rotor. Because of the overlapping cadmium regions and the rotation of the cadmium sections, the effect on reactivity is not proportional to the rotor position for all angles of rotation. The calibration of the pilot rod is necessary to determine the range of angles of rotation of the rotor that are proportional to reactivity, and to accurately determine the differential change in reactivity. The technique does not determine the absolute value of reactivity for a given rotor position, but instead is based on the relative reactivity effect, which is significantly more accurate for determining small changes in reactivity.

To calibrate the pilot rod for oscillation measurements, two stages of calibration are performed. The first stage deals with verifying that the reactivity range of the pilot rod matches the range of the sample reactivity, i.e. $\pm 0.0001(10 \mathrm{pcm})$. This is accomplished by positioning the pilot rod at different angles (i.e. different values of voltage on the rotor) and measuring the reactivity excess of the core. By doing this over the entire range of angles, a calibration curve of the pilot rod is created, as shown in Figure 15. This is a crude calibration that is adequate for initial positioning of the pilot rod but not sufficient for detailed measurements of small reactivity changes. 


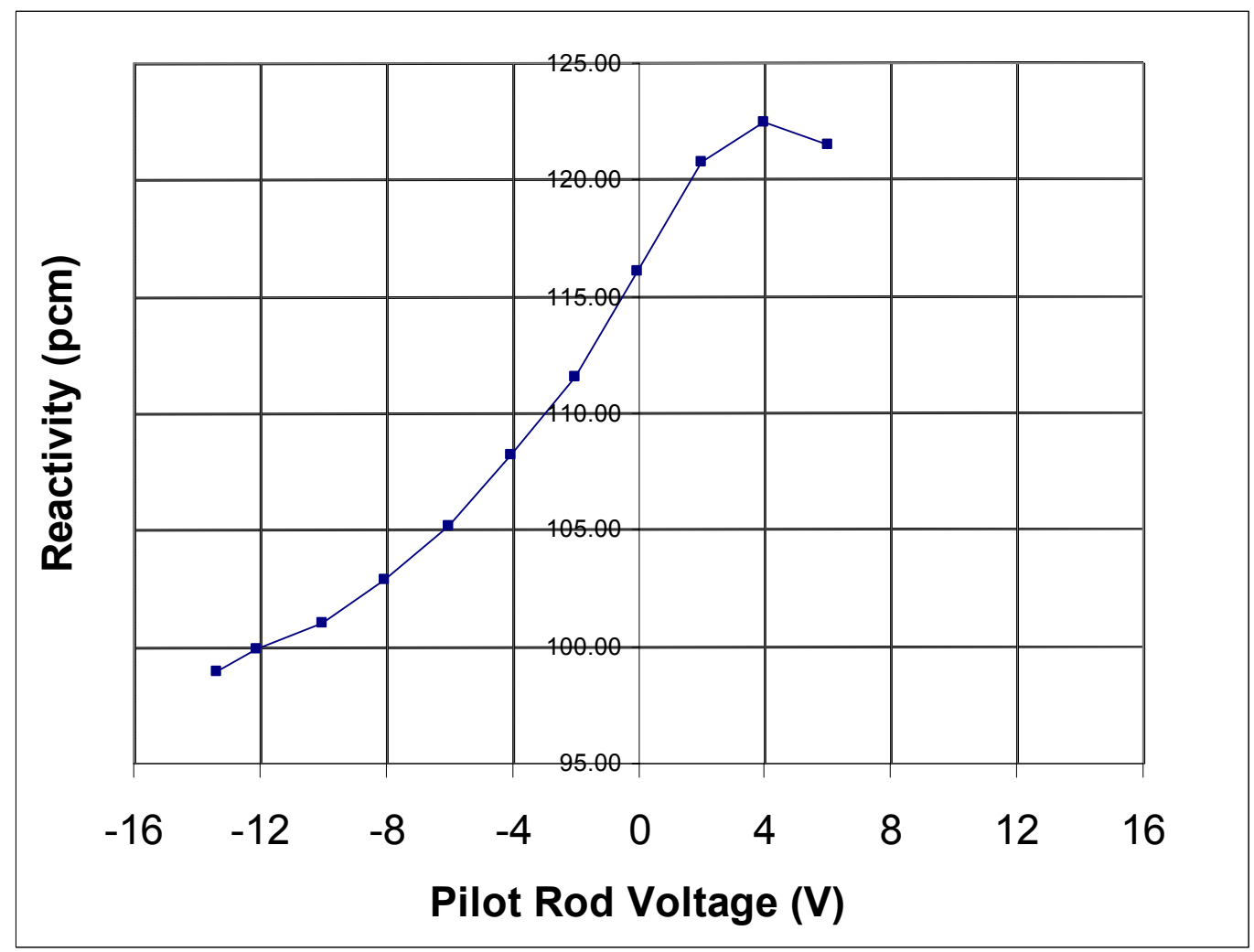

Figure 15: Reactivity curve of the pilot rod in the R1-MOX configuration

In the second stage of the calibration, the differential reactivity effect is determined for small changes in the voltage applied to the pilot rod. The position of the pilot rod is controlled by the bias voltage applied to the rotor. As observed in Figure 15, the change in reactivity effect is not directly proportional to the voltage. This means that the differential effects of applying a constant voltage to the rotor will also not be a constant effect, i.e. it will depend on the initial positioning of the rotor (or voltage applied to the rotor). This initial voltage is equivalent to the mean amplitude during the oscillations of the samples. So a calibration curve is created which relates the variation of the angle of the pilot rod (i.e. amplitude of the signal) to its mean angle (mean value of the signal). This relation is linear over a small range and allows the normalization of all measurements to a specified reference angle.

Figure 16 shows the calibration curve in R1-MOX (error bars are given at $1 \sigma$ ). In this region of linearity, the response from all samples can be directly compared based on the same reference angle $\theta_{0}$ using the following relationship:

$$
f(\theta)=f\left(\theta_{0}\right) \times\left(1+K \times\left(\theta-\theta_{0}\right)\right)
$$

with $\mathrm{f}(\theta)=$ measured amplitude, $\theta=$ mean position of the pilot rod during the measurement, $\theta_{0}=$ reference mean position (chosen in the middle of the linear part of the differential efficiency curve), $f\left(\theta_{0}\right)=$ amplitude of the signal if the measurement had been performed with a mean position of the pilot rod equal to $\theta_{0}$, and $\mathrm{K}=$ constant dependant on $\theta_{0}$ and on the linear equation of the differential efficiency curve. 


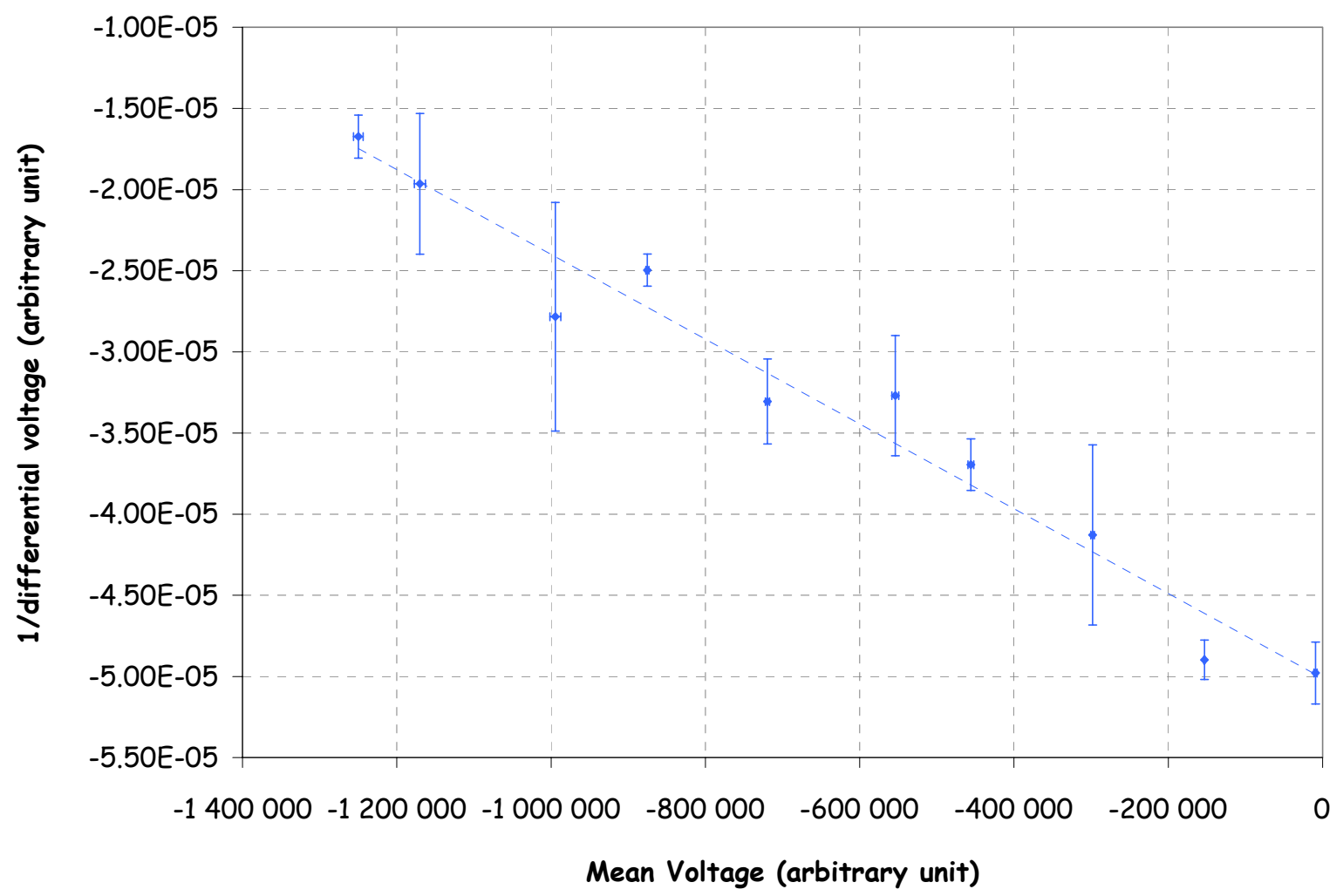

Figure 16: Differential efficiency curve of the pilot rod in the R1-UO2 configuration

The pilot rod calibration allows the reference angle $\theta_{0}$ to be established and the normalization factor $\mathrm{K}$ to be determined. This calibration then allows all of the oscillation measurements to be normalized to the same reference angle.

The reactivity worth of the four control and safety rods of the MINERVE facility loaded with the R1-MOX core configuration was measured in August 2006 prior the beginning of the oscillation measurements.

The reactivity worth of every control rod from its critical position to its lower position was measured using the rod drop technique. The reactivity worth from the critical position to the upper position was determined using a standard doubling time measurement.

For each rod drop measurement, the signal was recorded both with a fission chamber placed in the central channel of the experiment zone, and another chamber placed in the thermal channel (so called "thermal socket") in the periphery of the reactor. The experimental results differ versus the position of the fission chamber, and have to be corrected by MSM (Modified Source Multiplication) factors that still need to be calculated. 


\begin{tabular}{|c|c|c|c|c|}
\hline \multicolumn{5}{|c|}{ Table 15 } \\
Reactivity worth of the control rods in the R1-MOX core configuration of MINERVE
\end{tabular}

\begin{tabular}{|c|c|c|c|}
\hline \multicolumn{4}{|c|}{ Table 16 } \\
\hline First experimental results in the R1-MOX core configuration \\
\hline Name & $\begin{array}{c}\text { Measurement } \\
\text { date }\end{array}$ & $\begin{array}{c}\text { Signal } \\
\text { (arbitrary units) }\end{array}$ & $\begin{array}{c}\text { s.d. } \\
\text { (arbitrary units) }\end{array}$ \\
\hline H1 (0.25\% U-235) & $09 / 05 / 2006$ & 1987 & 1210 \\
\hline H2 (0.50\% U-235) & $09 / 05 / 2006$ & 9703 & 1321 \\
\hline H3 (0.71\% U-235) & $09 / 05 / 2006$ & 20258 & 1920 \\
\hline H4 (1\% U-235) & $09 / 05 / 2006$ & 25639 & 1809 \\
\hline H5 (2\% U-235) & $09 / 20 / 2006$ & 56348 & 2172 \\
\hline H6 (3\% U-235) & $09 / 20 / 2006$ & 82973 & 3024 \\
\hline
\end{tabular}

All the results are given in Table 15. Nevertheless, taking into account the beta effective value in the R1-MOX configuration ( $\beta \mathrm{eff}=681 \mathrm{pcm}$ ), the safety criteria on the reactivity worth of the control rods of MINERVE were respected, so that the experimental program in the R1-MOX configuration was allowed to be performed. Furthermore, the excess of reactivity of the core is $\$ 0.156( \pm \$ 0.006)$, so that it is largely below the safety criteria of $\$ 0.50$.

Upon completion of the safety authorization measurements and the calibration of the pilot rod in the R1-MOX configuration, oscillation measurements began in September 2006. The first experimental results are given in Table 16 for the U-235 calibration samples in the R1-MOX core configuration. Oscillation measurements will continue until June 2007 to complete all of the samples in the the R1-MOX configuration.

\subsection{Planned activities for 2007}

Figure 17 presents the schedule of measurements in the MINERVE reactor for the OSMOSE program. The OSMOSE program is performed in parallel to the OCEAN (Oscillation in Core of samplEs containing New Absorbers) program (funded by EDF and CEA). 


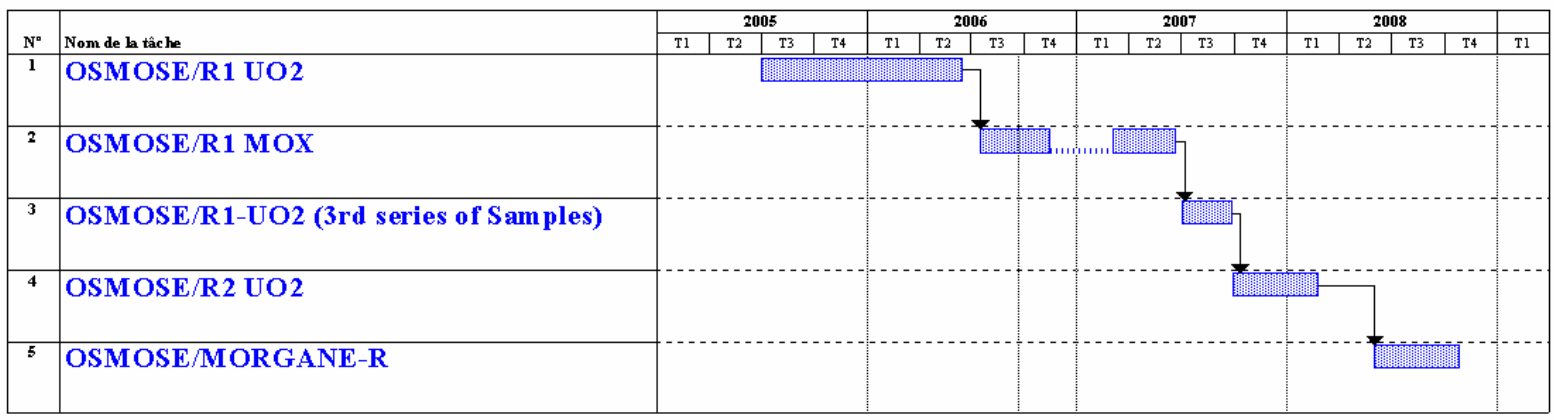

Figure 17: Planning of the OSMOSE Measurements

The experiments for the first and second sets of OSMOSE samples and calibration samples in the R1-MOX configuration will be completed by March 2007. The measurements with the third set of samples, including the 2 Curium samples, will be completed before July 2007.

The OSMOSE program will be performed in several core configurations until the end of 2008. In parallel, the French OCEAN program will be performed in the same configurations (so with the same calibration samples and the same calibration of the pilot rod), and MINERVE will also be used for training periods for EDF and students for 1 to 2 months/year.

The OSMOSE samples will be oscillated in the R2-UO2 configuration from October 2007 to March 2008 and in the MORGANE-R configuration from June 2008 to November 2008. A safety report and authorization will be requested for the R2-UO2 and the MORGANE-R core configurations in 2007. In particular, the adaptation of the new calculation scheme to the MORGANE-R loading (MOX 11\% fuel pins in a hexagonal pitch) will have to be performed. Furthermore, a separate safety authorization will be needed for measuring the Curium samples in all the core configurations.

\subsection{Issues and concerns}

There are no issues or concerns at this time. The experimental measurements are proceeding on schedule.

\section{DATA ANALYSIS}

\subsection{Objectives}

The data analysis tasks address the analysis and reduction of data for each series of measurements for the different core configurations. In general, the data analysis tasks include the review and analysis of the raw data for the full range of separated samples for the OSMOSE program in each reactor configuration, the analysis of the raw data from the calibration and test measurements performed with calibration samples of differing uranium and boron compositions, and the analysis of the raw data for all spectral indices and axial and radial distributions measurements performed to support the OSMOSE program. 
In addition, the data analysis tasks include processing the raw data from the instruments and data acquisition system to produce the experimental results, i.e. the analysis and reported sampleworth for each of the separated samples and calibration samples for all reactor configurations included in the OSMOSE program.

The objective of the data analysis tasks are to compile the data and results into a reactor physics benchmark (in accordance with guidance provided by the American Nuclear Society Joint Benchmark Committee), This benchmark includes a thorough review and study of the systematic errors in the measurement technique, measurements, and statistical uncertainties.

\subsection{Technical Status}

Data analysis activities related to pre-planning of the measurements and to support the calibration of the pilot rod and sample calibrations was discussed in previous sections.

The ANL and CEA data analysis are based on the same geometry and material balance of the MINERVE facility and of the OSMOSE samples. The material balance of the samples comes from the masses of natural $\mathrm{UO}_{2}$ and actinide inserted before fabrication inside samples. It needs to be confirmed by the post-fabrication chemical analysis, so the following calculation results are considered as preliminary.

\subsubsection{CEA model for data analysis}

The CEA model for data analysis is based on the APOLLO2 deterministic code with the JEF2.2 and the JEFF3.1 data libraries. It consists of a 2-dimensional (11x11) multi-cell calculation (see Figure 18), using the probabilities of collisions and 2D interface currents with imposed leakage. It is based on the current French PWR optimized calculation scheme, with SHEM-281 energy groups and space dependant self-shielding. More details about this model can be found in reference [7].

The APOLLO2 model was previously qualified on the basis of modified conversion ratio of U238 measurements [8]. Due to small differences in the height of the columns of pellets inside samples and to the axial flux distribution at the sample position, a length correction is applied to every sample taking into account the axial buckling. These corrections are generally less than $5 \%$ of the experimental signal. They are controlled with an accuracy of better than $0.5 \%(1 \sigma)$.

The $(C-E) / E$ comparison of the preliminary calculation results $(C)$ with experimental results $(E)$ is given in Table 17. An excellent overall uncertainty on $(C-E) / E$ of around $2 \%$ is obtained when combining quadratically the uncertainties associated to data analysis and experiments. 

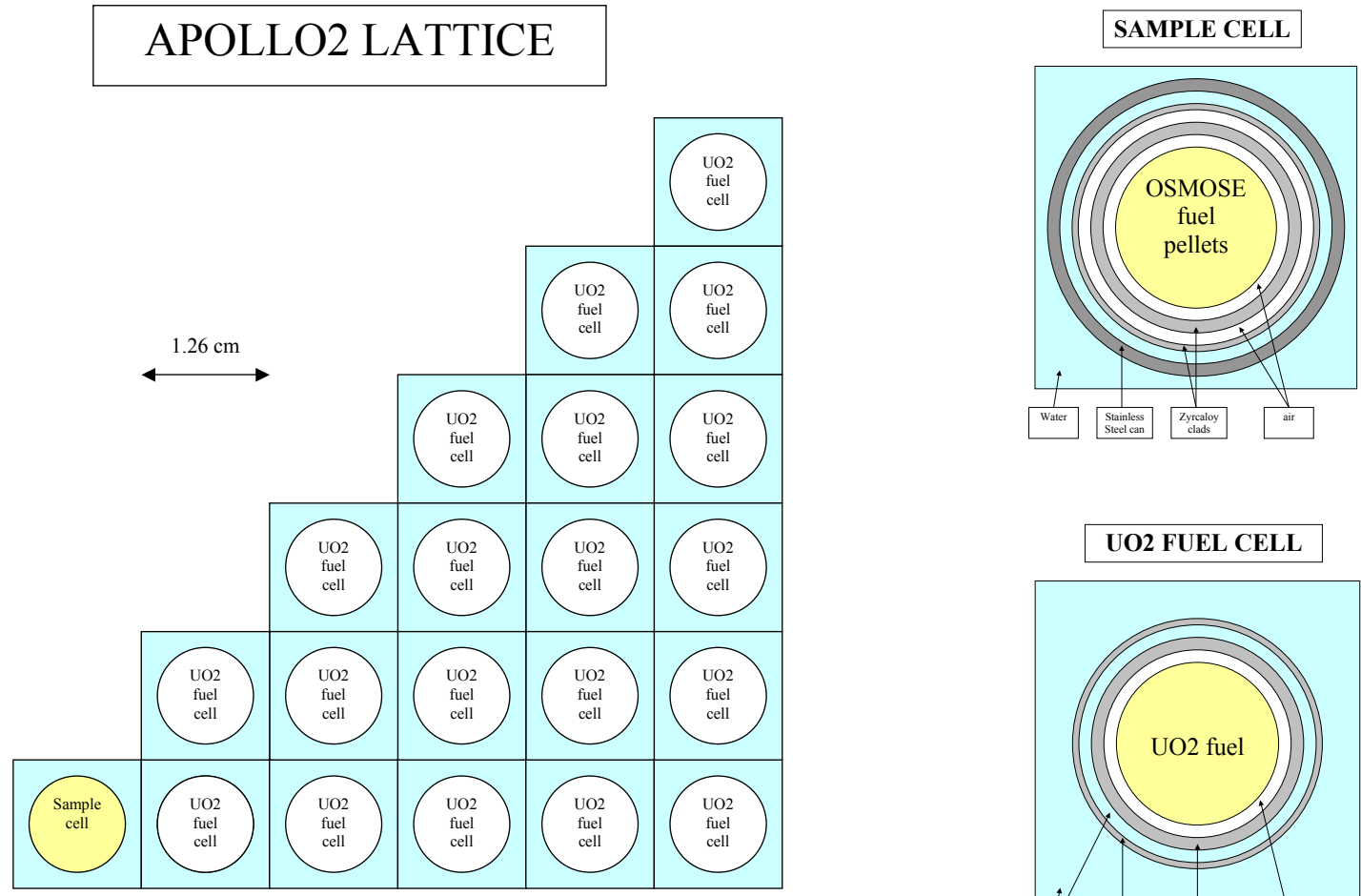

Figure 18: (11x11) multi-cell APOLLO2 calculation model

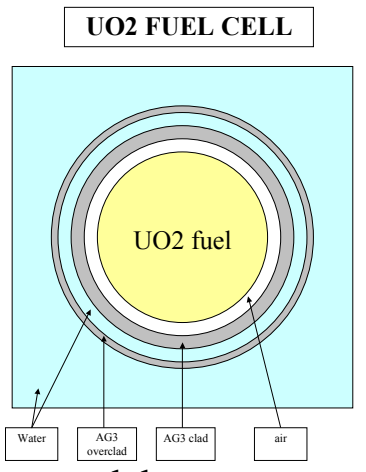

Table 17:

Comparison of experimental and calculated results with the APOLLO2 model

\begin{tabular}{|c|c|c|c|c|c|}
\hline \multirow{2}{*}{ Sample } & \multicolumn{2}{|c|}{$(\mathrm{C}-\mathrm{E}) / \mathrm{E}$ in $\%$} & \multirow{2}{*}{$\sigma_{\mathrm{d}}(\%)(\mathrm{a})$} & \multirow{2}{*}{$\sigma_{\mathrm{e}}(\%)(\mathrm{b})$} & \multirow{2}{*}{$\sigma_{\text {tot }}(\%)(\mathrm{c})$} \\
\cline { 2 - 3 } & $\mathrm{JEF} 2.2$ & $\mathrm{JEFF} 3.1$ & & $1.9 \%$ & $2.6 \%$ \\
\hline $\mathrm{Th}-232$ & $1.3 \%$ & $0.9 \%$ & $1.8 \%$ & $1.0 \%$ & $2.0 \%$ \\
\hline $\mathrm{U}-234$ & $-0.4 \%$ & $-6.2 \%$ & $1.8 \%$ & $0.4 \%$ & $1.8 \%$ \\
\hline $\mathrm{Pu}-239$ & $-0.7 \%$ & $0.8 \%$ & $1.8 \%$ & $1.0 \%$ & $2.1 \%$ \\
\hline $\mathrm{Pu}-242$ & $1.2 \%$ & $0.9 \%$ & $1.8 \%$ & $1.3 \%$ & $2.2 \%$ \\
\hline $\mathrm{Np}-237 / 1$ & $-10.0 \%$ & $-13.1 \%$ & $1.8 \%$ & $0.3 \%$ & $1.8 \%$ \\
\hline $\mathrm{Np}-237 / 2$ & $-7.4 \%$ & $-10.9 \%$ & $1.8 \%$ & & \\
\hline
\end{tabular}

(a) uncertainty on the data analysis

(b) experimental uncertainty

(c) total uncertainty on (C-E)/E 


\subsubsection{ANL model for data analysis}

The ANL model for data analysis is based on the lattice physics code DRAGON using ENDFB/VI 172 group neutron library. It consists of a two-dimensional $(11 \times 11)$ multi-cell calculation (see Figure 19), using the two-dimensional surface net current coupled collision probability method. The ANL model and analysis are described in detail in reference [9].

In DRAGON calculation, the critical buckling search is superimposed upon the iteration so that the effective multiplication factor $\left(\mathrm{k}_{\text {eff }}\right)$ is forced to 1.0 , and using the calculated flux, the infinite multiplication factor $\left(\mathrm{k}_{\text {inf }}\right)$ can be determined, this value is used as the calculated result for the analysis.

Using the function between $k_{\text {inf }}$ described in the reactor modeling section as well as the experimental results for the OSMOSE samples, the experimental $k_{\text {inf }}$ and reactivity worth of the OSMOSE samples can be predicted, and the comparison to the calculated results is shown in Table 18.

It can be seen that for the U-234, Pu-239 and Pu-242 samples, the calculation result agrees well with that of the experimental result. However, for the Np-237 samples there exists relatively large error. As the experimental signal of Np-237 is mainly due to both thermal and epithermal captures, it is difficult to identify whether the thermal part or the integral resonance or both of the Np-237 capture cross section are underestimated. It can also be observed that the calculated results always over-estimate the reactivity worth for the samples, ( although for some samples it only over estimates the reactivity worth slightly), which might be due to the error of the ENDF/B-VI data set.
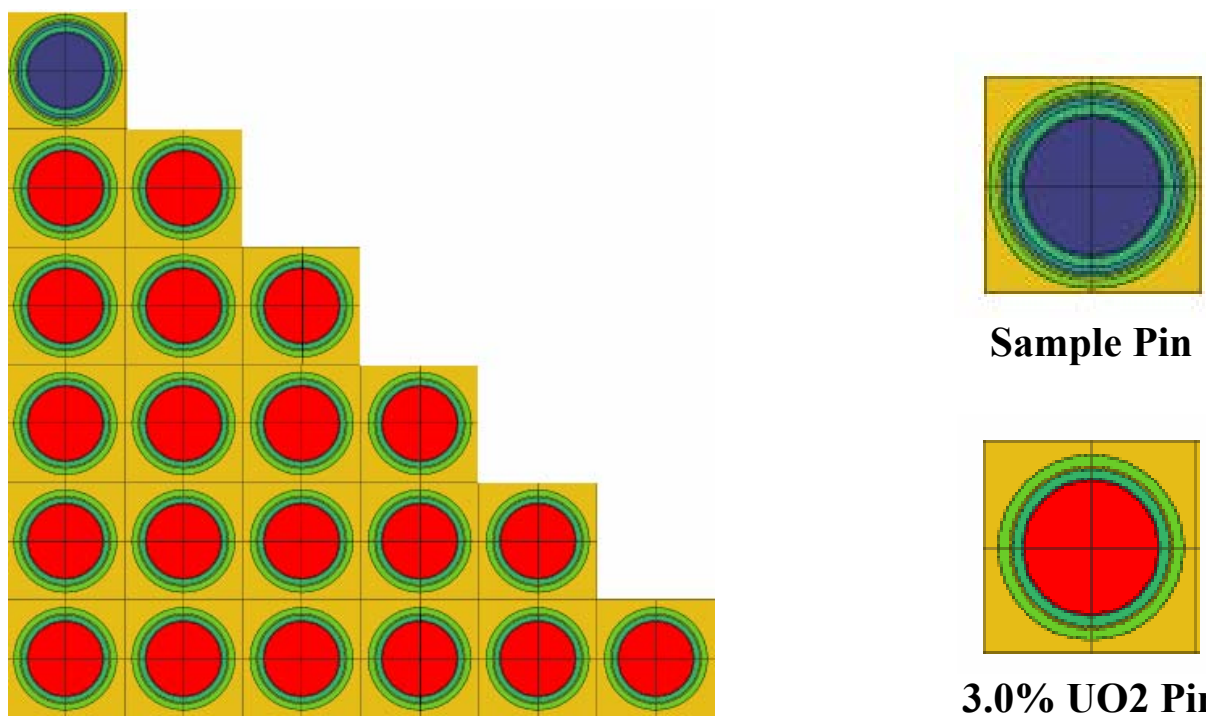

Sample Pin

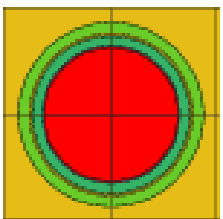

$3.0 \%$ UO2 Pin

Figure 19: DRAGON calculation model 
Table 18:

Comparison of experimental and calculated results with the DRAGON model

\begin{tabular}{|c|c|c|c|c|c|c|}
\hline \multirow[b]{2}{*}{ Sample } & \multirow{2}{*}{$\begin{array}{c}\text { Calculated } \\
\text { reactivity } \\
\text { worth } \\
(\mathrm{pcm})\end{array}$} & \multirow{2}{*}{$\begin{array}{l}\text { Experimental } \\
\text { reactivity } \\
\text { worth }(\mathrm{pcm})\end{array}$} & $(\mathrm{C}-\mathrm{E}) / \mathrm{E}$ in $\%$ & \multirow{2}{*}{$\begin{array}{c}\sigma_{d}(\%) \\
\text { (a) }\end{array}$} & \multirow{2}{*}{$\begin{array}{c}\sigma_{\mathrm{e}}(\%) \\
\text { (b) }\end{array}$} & \multirow{2}{*}{$\begin{array}{c}\sigma_{\text {tot }}(\%) \\
\text { (c) }\end{array}$} \\
\hline & & & ENDF-B/VI & & & \\
\hline U-234 & -27.31 & -26.18 & $4.3 \%$ & $2.3 \%$ & $1.0 \%$ & $2.5 \%$ \\
\hline Pu-239 & 72.74 & 72.34 & $0.5 \%$ & $2.3 \%$ & $0.4 \%$ & $2.3 \%$ \\
\hline $\mathrm{Pu}-242$ & -26.10 & -25.20 & $3.6 \%$ & $2.3 \%$ & $1.0 \%$ & $2.5 \%$ \\
\hline $\mathrm{Np}-237 / 1$ & -20.63 & -19.58 & $5.3 \%$ & $2.3 \%$ & $1.3 \%$ & $2.6 \%$ \\
\hline $\mathrm{Np}-237 / 2$ & -120.07 & -105.76 & $13.53 \%$ & $2.3 \%$ & $0.3 \%$ & $2.3 \%$ \\
\hline
\end{tabular}

(a) uncertainty on the data analysis

(b) experimental uncertainty

(c) total uncertainty on (C-E)/E

Table 19:

Comparison of the calculated (C) and experimental (E) results

\begin{tabular}{|c|c|c|c|c|c|c|}
\hline & \multicolumn{3}{|c|}{ IAEA- ENDF/B-VI REV.8 } & \multicolumn{3}{c|}{$\begin{array}{c}\text { IAEA- JEFF3.1 } \\
172-\mathrm{g} \text { library }\end{array}$} \\
\hline Sample & $\begin{array}{c}\mathrm{C} \\
(\mathrm{pcm})\end{array}$ & $\begin{array}{c}\mathrm{E} \\
(\mathrm{pcm})\end{array}$ & $\begin{array}{c}(\mathrm{C}-\mathrm{E}) / \mathrm{E} \\
\mathrm{in} \%\end{array}$ & $\begin{array}{c}\mathrm{C} \\
(\mathrm{pcm})\end{array}$ & $\begin{array}{c}\mathrm{E} \\
(\mathrm{pcm})\end{array}$ & $\begin{array}{c}(\mathrm{C}-\mathrm{E}) / \mathrm{E} \text { in } \\
\%\end{array}$ \\
\hline $\mathrm{U}-234$ & -27.36 & -26.06 & $5.0 \%$ & -26.26 & -25.99 & $1.1 \%$ \\
\hline $\mathrm{Pu}-239$ & 72.60 & 72.02 & $0.8 \%$ & 71.96 & 71.82 & $0.2 \%$ \\
\hline $\mathrm{Pu}-242$ & -26.50 & -25.08 & $5.7 \%$ & -25.12 & -25.01 & $0.4 \%$ \\
\hline $\mathrm{Np}-237 / 1$ & -21.12 & -19.50 & $8.3 \%$ & -19.98 & -19.44 & $2.8 \%$ \\
\hline $\mathrm{Np}-237 / 2$ & -122.25 & -105.29 & $16.1 \%$ & -115.47 & -104.99 & $10.0 \%$ \\
\hline $\mathrm{U}-\mathrm{TH} 32$ & -15.91 & -16.10 & $-1.2 \%$ & -16.04 & -16.05 & $-0.1 \%$ \\
\hline
\end{tabular}

Although this discrepancy between the calculated and experimental results is observed, it is still difficult to conclude whether this problem is caused by the ENDF/B-VI data itself or is inherent in the processing of the data for the multi-group calculations. The DRAGON library is not raw ENDF/B data, a lot of pre-processing has been performed, especially for the resonance region where some approximations have been introduced to calculate the resonance integrals. New WIMSD format 172-group libraries based on ENDF/B-VI rev.8 and JEFF3.1 were downloaded from the IAEA website, and these were transformed into a binary format that could be used by the lattice physics code DRAGON. These new libraries provide us a chance for further validation of the nuclear data set. Using the new IAEA library, a similiar comparison between calculated and experimental reactivity worth was performed, which is shown in Table 19. 
From the results shown in Table 19, the results using ANL ENDF/B-VI library are consistent with that using IAEA ENDF/B-VI library. The ANL library appears even to be a little better, the possibily due to the more detailed treatment of anisotropic scattering. It can also be seen that the agreement between calculated and experimental results using the JEFF3.1 library is apparently better than that using ENDF/B-VI library. However there still exists relatively large difference between the calculated and experimental results for $\mathrm{N}_{P}$ samples.

Based on this, it is concluded that the large discrepancy between calculated and experimental results for the $\mathrm{Np}$ sample is not library specific. The possible sources of error are 1) sample composition and geometry, 2) raw data in ENDF and JEFF, 3) self-shielding parameters in the processed library, but it is suspected to be due to the ENDF/VI and JEFF data set. Additional study will be performed to determine the source of error.

\subsubsection{Uncertainties related to the data analysis}

Table 20 summarizes the uncertainties on the data analysis. A standard overall uncertainty of $1.8 \%$ is obtained in each case. In the future, this uncertainty could be slightly reduced taking into account the post-fabrication chemical analysis on control fuel pellets.

\begin{tabular}{|c|c|}
\hline \multicolumn{2}{|c|}{ Table 20 } \\
Standard Relative Uncertainties Related to the Data Analysis \\
\hline Material balance of the calibration samples (a) (b) & $1 \%$ \\
\hline Length corrections (a) & $0.5 \%$ \\
\hline Nuclear data about B-10 and U-235 (a) & $<1 \%$ \\
\hline Slope of the calibration curve & $1.5 \%$ \\
\hline Material balance of the OSMOSE samples (b) & $1 \%$ \\
\hline Overall uncertainty on data analysis & $1.8 \%$ \\
\hline
\end{tabular}

(a) taken into account in the uncertainty for the determination of the slope of the calibration curve

(b) uncertainty on the material balance known from weighing before fabrication

\subsubsection{Comparison of ANL and CEA results}

An excellent agreement (within $1 \sigma$ ) between APOLLO2 and DRAGON calculation results is obtained for Th-232, Pu-239, and Pu-242, with JEF2.2 and JEFF3.1 data libraries. The results with ENDF/B-VI are consistent for the Th-232 and Pu-239 samples. There are discrepancies for U-234 and Np-237 between the two models. These may be a result of potential material balance or self-shielding differences in the models. Further investigation is ongoing to determine and resolve these differences.

A good agreement (within $2 \sigma$ ) between APOLLO2 and DRAGON calculation results and experimental results is obtained for all cases except Np-237 and U-234 with the JEFF3.1 library and the APOLLO model. 
For Np-237, consistent C/E results are obtained for the two samples. They show an underestimation of the calculation of about $8 \%$ with JEF2.2 and 13\% with JEFF3.1. As the signal of Np-237 is mainly due to both thermal and epithermal captures, it is not possible to identify whether the thermal part or the integral resonance or both, of the Np-237 capture cross section are underestimated. The future trends on $\mathrm{C} / \mathrm{Es}$ that will be obtained in future core configurations should allow us to identify more precisely the origin of the deviation between calculation and experimental results.

The DRAGON model results appear to show a systematic bias such that all of the calculated values are higher than the experimentally measured values. Otherwise, they are reasonably consistent with the APOLLO2 model results. The DRAGON model has not yet been validated and there are several potential sources of the bias and discrepancy between the results and those from the APOLLO2 model: 1. self-shielding effects may not have been appropriately considered in collapsing from the continuous energy cross-sections to the multi-group cross-sections especially in the case of the minor actinides, 2. the DRAGON model did not account for the slight variation in sample height as discussed in the APOLLO2 model, 3. there may be a small bias in the calibration curve based on the model of the calibration samples, and 4. there may still be some minor differences in the compositions of the samples. The differences in the results are still being investigated.

\subsection{Planned activities for 2007}

Significant data analysis activities are planned for FY07. The measurement data for the first two sets of OSMOSE samples in the R1-UO2 configuration will be completely treated and a first benchmark report will be drafted.

The measurement data for all of the OSMOSE samples in the R1-MOX configuration will be completely treated and a benchmark report will be drafted. The issuance of the benchmark reports may be delayed pending the chemical analysis and confirmation of the sample compositions.

Analyses will be performed to address several key technical questions. Specifically, the relevance of the OSMOSE configurations to the block-type VHTR, the GCR, and other Gen-IV concepts will be studied. The neutron spectra of the different OSMOSE configurations will be compared to the representative spectra for the Gen-IV concepts. As presented here, some analysis for several of the MINERVE spectra and relevant Gen-IV spectra have begun. These analyses and comparisons will be formalized and further developed in 2007.

\subsection{Issues and Concerns}

There are no significant issues or concerns at this time. ANL and CEA are working to resolve discrepancies and differences in the data analysis activities that are reported here and to develop a common methodology for performing data analysis in 2007 and for future measurements. 


\section{SUMMARY AND CONCLUSIONS}

The goal of the OSMOSE program is to measure the reactivity effect of minor actinides in known neutron spectra of interest to the Generation-IV reactor program and other programs and to create a database of these results for use as an international benchmark for the minor actinides. The results are then compared to calculation models to verify and validate integral cross-sections for the minor actinides.

The OSMOSE program includes all aspects of the experimental program - including the fabrication of fuel pellets and samples, the oscillation of the samples in the MINERVE reactor for the measurement of the reactivity effect, reactor physics modeling of the MINERVE reactor, and the data analysis and interpretation of the experimental results.

Significant accomplishments in FY06 include: 1. the completion of the oscillation measurements in the R1-UO2 core configuration (PWR-Uox spectrum) for the first 2 sets of OSMOSE samples, 2. the completion of data analysis with both APOLLO2 and DRAGON deterministic calculation codes, respectively in CEA and ANL, and the comparison of experimental results of the first 2 sets of samples in R1-UO2 to calculational results, 3. the fabrication and shipment to CEA Cadarache of the second set of OSMOSE samples, 4. the completion of chemical and isotopic analysis of the first set of samples at CEA Marcoule, 5. the loading of the R1-MOX core configuration in July 2006, 6. the beginning of the oscillation measurements in the R1-MOX core configuration (PWR-MOX spectrum) in September 2006, 7. the publication of the OSMOSE results in R1-UO2 at the PHYSOR2006 conference, including the comparison of experimental results with ANL and CEA calculation results and the publication of four ANL technical reports and three CEA reports related to the OSMOSE project.

\section{FUTURE ACTIVITIES AND CONTINUED COLLABORATION}

The continuation of the DOE/CEA collaboration on the OSMOSE program includes the participation of DOE in the conduct of the experiments and the development and comparison of analytic tools and models of CEA and DOE based on Monte Carlo and deterministic methods. CEA continues to support and fund the experimental and analytical programs at the CEA Cadarache Research Center. The U.S. involvement in the program was supported in 2006 as part of the ANL-Model Improvement work package within the Generation-IV program. In 2007, the U.S. involvement is being supported by the Advanced Fuel Cycle Initiative. The project is also continuing as a collaboration between DOE and CEA within the guidelines of the new I-NERI program.

Safety authorization will be requested for the R2-UO2 and the MORGANE-R core configurations. In particular, the adaptation of the new calculation scheme to the MORGANE-R loading (MOX 11\% fuel pins in an hexagonal pitch) will have to be performed. Furthermore, a separate safety authorization will be needed for measuring the Curium samples in all the core configurations.

Within the framework of the new Global Nuclear Energy Partnership (GNEP) and the OSMOSE I-NERI collaboration, ideas for extending the collaboration have been evoked during 2006. 
There are several critical issues that need to be addressed within the framework of the OSMOSE program, the GNEP program, and future collaborations with CEA. Specifically, the questions that need to be addressed are:

1. How do the spectra in the MINERVE core loadings compare to representative spectra of the Gen-IV and GNEP concepts.

2. If the spectra do not compare, what would be the approach for developing a new core configuration that would allow the spectra to closely match the spectra for the concepts?

3. For harder neutron spectra (like in the MORGANE-S and ERMINE loadings or in new loadings), what types of samples are necessary for accurate measurements?

4. What would be the approach for fabricating additional samples for these configurations?

5. Is there a programmatic interest in conducting Doppler-broadening measurements?

6. Can the OSMOSE samples and MINERVE facility be used to perform Dopplerbroadening measurements? And if so, what types of modifications would be required?

Within the framework of the GEN-IV future concepts and of the OSMOSE I-NERI collaboration, ideas for extending the collaboration have been evoked during 2006. For instance, it would be interesting to oscillate the OSMOSE samples (or similar samples, or even structural materials) in core configurations representative of SFR, VHTR or GCR concepts. During these experiments, it could also be interesting to study the Doppler effect by heating the samples to high temperatures.

A working group between CEA and ANL will meet in October 2006 for studying the feasibility of such program extensions. It will particularly study the possibilities to conceive new and adapted core configurations inside the MINERVE facility, to fabricate new samples adapted to new core configurations (i.e. new and harder neutron spectra) and to identify requirements, needs, and limitations for the proposed new configurations and measurements.

\section{MILESTONES AND DELIVERABLES}

Milestones for the OSMOSE program for FY06 are defined in work package number GA0802L01. The milestones and deliverables are excerpted from the work package and listed below in Table 21.

This report (ANL-Gen-IV-085) and the following list of reports are the deliverables to meet the established milestones and commitments for FY06:

1. G. Stoven, R.Klann, J.P. Hudelot, Gamma-Spectroscopy Measurements on Irradiated Fuel Pins - Application to Normalization of Power Distributions in the MINERVE R1MOX Core, ANL Report ANL-GEN-IV-073, September 1, 2006.

2. G. Stoven, R. Klann, OSMOSE Program: Statistical Review of Oscillation Measurements in the MINERVE Reactor R1-UO2 Configuration, ANL Report ANL-GEN-IV-078, September 1, 2006.

3. Z. Zhong, R. Klann, G.Stoven, Results of Calculations for the OSMOSE Samples in the MINERVE Reactor R1-UO2, R2-UO2, and R1-MOX Configurations, ANL Report ANLGEN-IV-084, September 27, 2006. 
ANL-Gen-IV-085

Table 21

Activities, Milestones, and Deliverables

\begin{tabular}{|c|c|l|c|c|}
\hline $\begin{array}{c}\text { Activity } \\
\text { Number }\end{array}$ & Level & Description & $\begin{array}{c}\text { Start } \\
\text { Date }\end{array}$ & $\begin{array}{c}\text { Finish } \\
\text { Date }\end{array}$ \\
\hline 1 & A & Participate in OSMOSE measurements and analysis & $10 / 1 / 05$ & $9 / 30 / 06$ \\
\hline 2 & 3 & Issue report on contribution to OSMOSE program & $9 / 30 / 06$ & $9 / 30 / 06$ \\
\hline 3 & D & Issue report on contribution to OSMOSE program & $9 / 30 / 06$ & $9 / 30 / 06$ \\
\hline
\end{tabular}




\section{REFERENCES}

[1] M. Salvatores, Experimental Facilities, Training and Expertise in the Nuclear Data Field: Needs and Gaps for Reactor Physics Applications, Conference Proceedings, Vol. 59, Nuclear Data for Science and Technology, G. Reffo, A. Ventura and C. Grandi (eds.), SIF, Bologna, 1997.

[2] G. Palmiotti, et al., Uncertainty Assessment for Accelerator Driven Systems, Proceedings of GLOBAL99, Jackson Hole, WY, September, 1999.

[3] P. Finck, et al., Activities of the OECD NEANSC Working Party on International Evaluation Cooperation, Conference Proceedings, Vol. 59, Nuclear Data for Science and Technology, G. Reffo, A. Ventura and C. Grandi (eds.), SIF, Bologna, 1997.

[4] JP. Chauvin, et al., "The MINERVE facility and the OSMOSE program", ANS-San Diego June 2000, USA.

[5] R. C. Potter et al., Gas Turbine-Modular Helium Reactor (GTMHR) Conceptual Design Description Report, GA Report 910720, Revision 1, General Atomics, July 1996.

[6] JP. Hudelot et al., Measurement of the modified conversion ratio of ${ }^{238} \mathrm{U}$ by gamma-ray spectrometry on an irradiated fuel pin, CGS11 Conference, 11th international symposium on capture gamma-ray spectroscopy, Prague, September 2002.

[7] D. Bernard, A. Courcelle, O. Litaize, A. Santamarina, M. Antony, JP. Hudelot, Validation of Actinide Neutron Induced Cross-Sections - Preliminary Analysis of the OSMOSE experiment in MINERVE, Proceedings of the PHYSOR 2006 Topical Meeting, September, 2006.

[8] R.T. Klann et al., MINERVE Reactor Characterization in Support of the OSMOSE Program: Spectral Indices, Proceedings of the PHYSOR-2004 Topical Meeting, April, 2004.

[9] Z. Zhong, R. Klann, G.Stoven, Results of Calculations for the OSMOSE Samples in the MINERVE Reactor R1-UO2, R2-UO2, and R1-MOX Configurations, ANL Report ANLGEN-IV-084, September 27, 2006. 
Argonne

Nuclear Engineering Division

Argonne National Laboratory

9700 South Cass Avenue, BIdg. 308

Argonne, IL 60439-4842

www.anl.gov

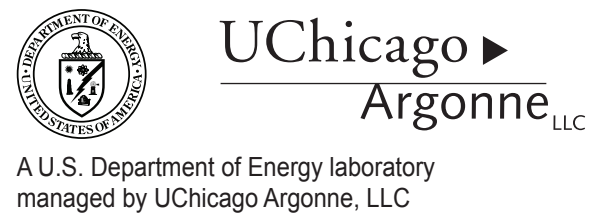

